ARTICLE

Received 21 Aug 2014 | Accepted 18 Nov 2014 | Published 6 Jan 2015

DOI: $10.1038 /$ ncomms 6894

OPEN

\title{
Centromeric binding and activity of Protein Phosphatase 4
}

\author{
Zoltan Lipinszki ${ }^{1}$, Stephane Lefevre ${ }^{2}$, Matthew S. Savoian ${ }^{1}{ }^{\dagger}$, Martin R. Singleton ${ }^{2}$, David M. Glover ${ }^{1}$ \\ \& Marcin R. Przewloka ${ }^{1}$
}

The cell division cycle requires tight coupling between protein phosphorylation and dephosphorylation. However, understanding the cell cycle roles of multimeric protein phosphatases has been limited by the lack of knowledge of how their diverse regulatory subunits target highly conserved catalytic subunits to their sites of action. Phosphoprotein phosphatase 4 (PP4) has been recently shown to participate in the regulation of cell cycle progression. We now find that the EVH1 domain of the regulatory subunit 3 of Drosophila PP4, Falafel (FIfI), directly interacts with the centromeric protein C (CENP-C). Unlike other EVH1 domains that interact with proline-rich ligands, the crystal structure of the FIfl amino-terminal EVH1 domain bound to a CENP-C peptide reveals a new target-recognition mode for the phosphatase subunit. We also show that binding of FIfl to CENP-C is required to bring PP4 activity to centromeres to maintain CENP-C and attached core kinetochore proteins at chromosomes during mitosis.

\footnotetext{
${ }^{1}$ Department of Genetics, University of Cambridge, Downing Street, Cambridge CB2 3EH, UK. ${ }^{2}$ Macromolecular Structure and Function Laboratory, Cancer Research UK, London Research Institute, London WC2A 3LY, UK. † Present address: Institute of Fundamental Sciences, Massey University, Private Bag 11222, Palmerston North 4442, New Zealand. Correspondence and requests for materials should be addressed to D.M.G. (email: dmg25@cam.ac.uk) or to M.R.P. (email: mrp50@cam.ac.uk).
} 
$\mathrm{R}$ eversible protein phosphorylation is a highly conserved regulatory mechanism that is crucial for orchestrating fundamental physiological processes such as cell division. Several members of the large phosphoprotein phosphatase (PPP) family of Ser/Thr phosphatases (the PP1-related family; the PP2A family of PP2A, PP4 and PP6; PP2B and PP5) have been linked to mitotic regulation ${ }^{1}$. However, our understanding of these enzymes is largely incomplete, in part because of the highly conserved nature of the catalytic subunits that rely on a wide range of targeting subunits to provide specificity. Much of our insight is based on PP1 and PP2A (refs 1,2), with little data available on the substrates and regulation of the other PPP family members.

Recent studies revealed that protein phosphatase 4 (PP4), a ubiquitous and essential PPP, regulates a variety of cellular processes $^{3}$, including chromatin biology ${ }^{4}$, DNA repair ${ }^{5-7}$ and cell cycle progression $^{8-10}$. Surprisingly, very few PP4 substrates have been identified so far. Like its family member PP2A (ref. 1), PP4 often functions as a heterotrimeric complex ${ }^{3,11}$ consisting of one evolutionarily conserved catalytic subunit (PP4c) that associates with two types of regulatory subunits: a structural protein, PP4R2 (R2, and R1 in mammals), and a regulatory 3 (R3) subunit, PP4R3 (platinum sensitivity 2 (Psy2) in yeast ${ }^{12,13}$, Falafel (Flfl) ${ }^{14}$ in Drosophila, suppressor of MEK1 (SMEK1; termed R3 $\alpha^{11}$ ) and SMEK2 (termed R3 $\beta^{11}$ ), the two known isoforms in human). The major form of PP4, conserved from yeast to human cells, comprises PP4c in complex with R2 and R3. However, in metazoans $\mathrm{PP} 4 \mathrm{c}$ can also associate with other ancillary proteins (for example, R4, HDAC3, $\alpha 4$ or Gemin4 (see refs 3,11 and 15)). Accordingly, PP4c has been found to be a component of several mutually exclusive complexes including the PP4c-R2-R3 (R3 $\alpha$ or $\beta$ ) heterotrimer, but also PP4c-R1-HDAC3, PP4c-R4 or PP4c- $\alpha 4$, that presumably have distinct substrates and biological roles. Current models propose that PP4 functions through the modular activity of its component subunits. But how these regulators cooperate in substrate selectivity or sub-cellular localization and stabilization of the holoenzyme is poorly understood.

A recent study, for example, indicates that the $\mathrm{PP} 4 \mathrm{c}-\mathrm{R} 3 \beta$ complex does not require other regulatory subunits (for example, $\mathrm{R} 2$ or R1) to dephosphorylate 53BP1 in DNA repair processes ${ }^{6}$. In contrast, other studies demonstrate that both $\mathrm{R} 2$ and $\mathrm{R} 3 \alpha$ are necessary to target $\mathrm{PP} 4 \mathrm{c}$ to the centrosomes ${ }^{16}$. Two studies suggest that the R3 subunit can target PP4c to its substrate. Human $\mathrm{R} 3 \alpha$, SMEK1, is reported to interact with the cell polarity protein Par3 to mediate its dephosphorylation by PP4c in the regulation of neuronal differentiation ${ }^{17}$. Furthermore, yeast R3, Psy2, specifically interacts with the glucose signal transducer protein Mth1 as a prerequisite for the PP4c-R3-mediated dephosphorylation of both Mth1 and a transcriptional repressor, Rgt1 (see ref. 18). These studies suggest that R3s are substrate-targeting subunits of PP4 but how substrate specificity is achieved remains unknown.

R3 orthologues are conserved throughout evolution with similar domain architecture and have been found from yeasts to human ${ }^{11,17-19}$ (Fig. 1a). They possess a predicted, conserved pleckstrin homology $(\mathrm{PH})$ superfamily-like domain and Smk-1/ DUF625 (Domain with Unknown Function 625, which is present in Smk-1 protein, a component of the IIs longevity pathway that regulates aging in Caenorhabditis elegans ${ }^{20}$ ) domain occupying the amino-terminal region of the protein. These domains are followed by a variable number of ARM (armadillo/HEAT repeats) in the middle and a carboxy-terminal unstructured (low complexity region) tail, which varies in length between different species (Fig. 1a).

Flfl $^{14}$, the R3-type subunit of Drosophila PP4, has been shown to bind Miranda (Mira) and so recruits PP4 $\left(\mathrm{PP} 4 \mathrm{c}-\mathrm{R} 2-\mathrm{R} 3^{\text {Falafel }}\right)$ to regulate asymmetric division of neuroblasts ${ }^{19}$. However, PP4's substrate in this process is unknown. Here we show that Flfl directly binds the centromeric protein $\mathrm{C}$ (CENP-C) and brings PP4 activity to centromeres. CENP-C is the key centromeric protein that provides a platform for kinetochore assembly and so bridges the mitotic centromere with core kinetochore proteins, which is critical for proper chromosome segregation ${ }^{21,22}$. We have precisely dissected the binding surfaces between Flfl and CENP$\mathrm{C}$ and now present the first crystal structure of the EVH1 domain (which belongs to the family of PH-like domains ${ }^{23}$ ) of the R3 subunit of PP4 in complex with CENP-C. Interestingly, the sequence defining this new variant of the EVH1 fold and the residues crucial for CENP-C/substrate binding are well conserved in all orthologues of PP4R3. We show that PP4 activity is required for the dephosphorylation of both Flfl and CENP-C. Moreover, the Flfl-CENP-C interaction brings PP4 catalytic activity to centromeres and this is critical in regulating the integrity of the mitotic centromeres and associated kinetochore proteins. Thus these functional and structural data provide new insights into PP4 function and the regulation of cell division.

\section{Results}

PP4 directly interacts with CENP-C. We have previously demonstrated that Drosophila PP4 has critical roles in cell cycle progression $^{8}$. As with other members of the PP2A family, the specificity of PP4 is thought to lie with interactions governed by its regulatory subunits. Therefore we wished to identify proteins interacting with Flfl, the R3-type subunit of Drosophila PP4. To this end, we established a Drosophila D.Mel-2 cell line expressing a Flfl::protein A fusion protein that we could affinity purify in complex with its associated proteins. Mass spectrometry identified components of the PP4 trimer consisting of Flfl (bait), PP4c and R2. CENP-C was also identified with high coverage and Mascot scores, indicating that it is a prominent partner of Flfl in this cell line (Table 1). To confirm that CENP-C also interacts with Flfl, we carried out the reciprocal experiment of establishing a D.Mel-2 cell line expressing a CENP-C::protein A. In this case, mass spectrometry identified all three subunits of PP4, including Flfl (Table 2). Moreover, similar results were obtained using either protein A-tagged Flfl or CENP-C expressed in Drosophila syncytial embryos (Supplementary Tables 1 and 2). Thus the interaction is not unique to cultured cells and is present during normal Drosophila development.

To determine which of the three PP4 subunits, if any, directly interacts with CENP-C, we synthesized each ${ }^{35}$ S-Met-labelled subunit using in vitro transcription-translation (IVTT) and identified which would bind to immobilized glutatione S-transferase (GST)-tagged full-length CENP-C. Of the three subunits, only Flfl directly interacted with CENP-C (Fig. 1b).

As a major centromeric component, CENP-C shows distinct centromeric localization throughout the cell cycle. To determine whether Flfl also localizes at centromeres, we generated an antiFlfl antibody (Supplementary Fig. 1a) and used this to investigate Flfl's sub-cellular localization by indirect immunofluorescence (IF). This revealed Flfl to be a predominantly nuclear protein, a proportion of which co-localized with a centromeric marker, the histone variant CENP-A (centromere identifier (CID), in Drosophila; Fig. 1c). This accords with the association of Flfl with centromeric CENP-C as shown by proteomics and in vitro binding assays. Together these data indicate that PP4 is a component of the Drosophila centromere that associates with CENP-C through a direct interaction made by its R3 subunit, Flfl.

Flfl binding domain of CENP-C recruits PP4 to centromeres. To narrow down the interacting surfaces between Flfl and 
a

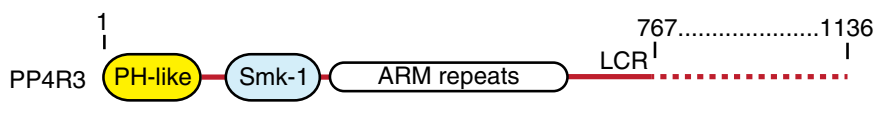

Falafel $\underbrace{102}_{\mathrm{Flf|N}}$

C
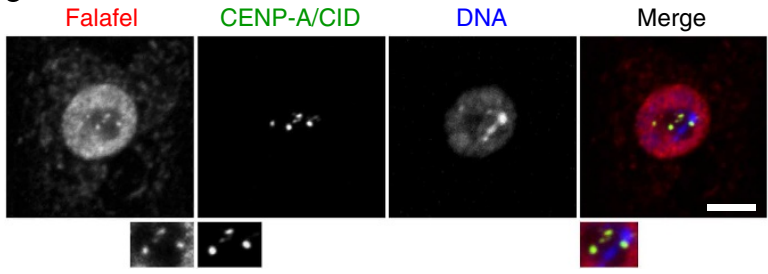

e
Carboxy-terminal fragment of CENP-C

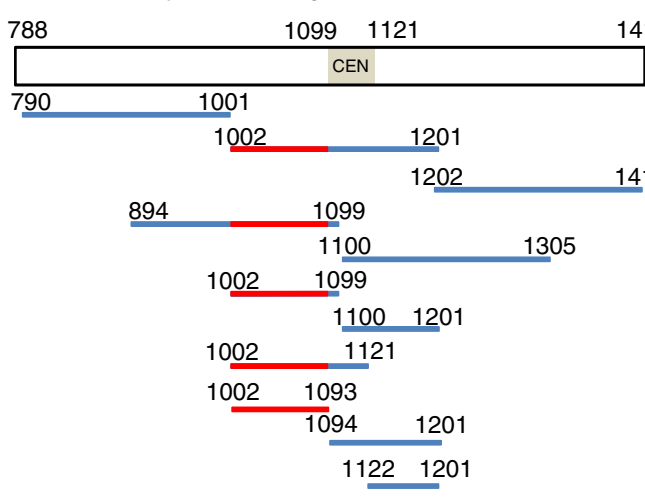
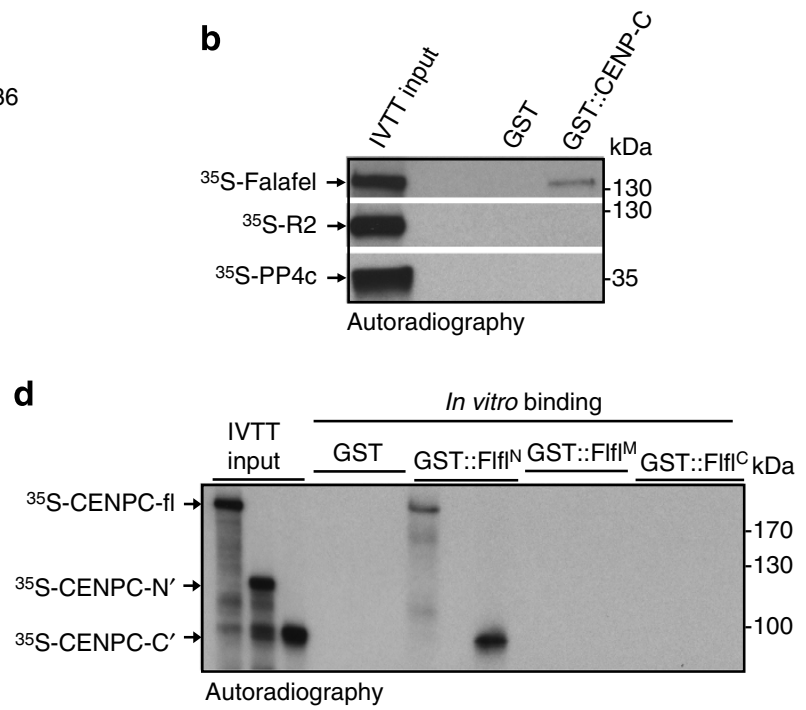
Name C1 C2 C3 $\mathrm{C} 4$ C5

C6 $\mathrm{C} 7$ $\mathrm{C} 8$ C9 (FBD) $\mathrm{C} 10$

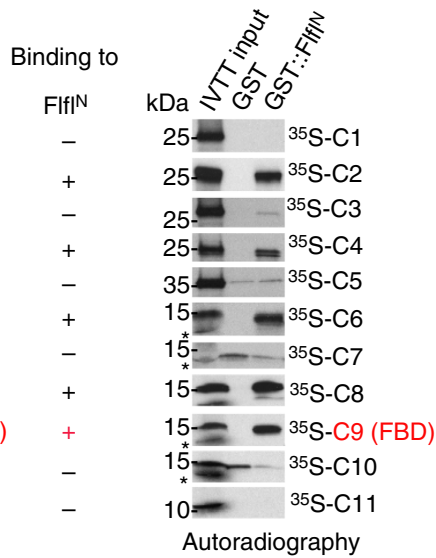

f

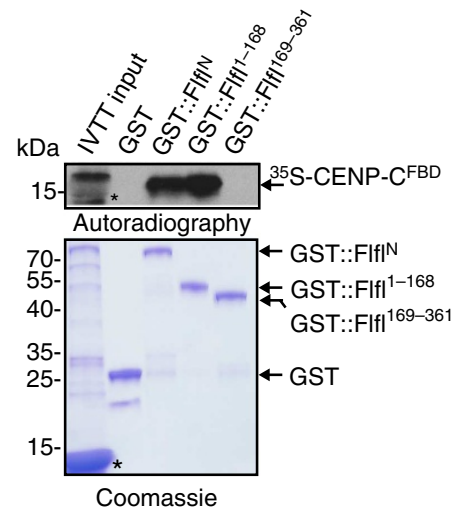

g

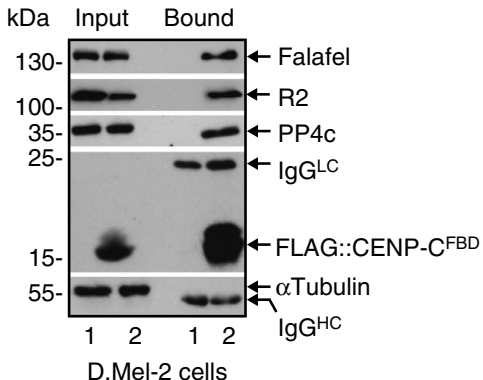

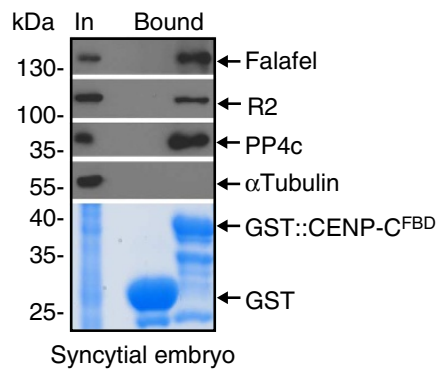

Figure 1 | Interacting domains of Falafel and CENP-C. (a) Schematic representation of the common structural elements of PP4R3 proteins compared with Drosophila R3, Falafel. R3s contain a conserved PH/EVH1-like domain and Smk-1 domain with unknown function in their N-termini, followed by Armadillo/ HEAT repeats (ARM) in the middle and a variable length (dotted line, according to HomoloGene R3 orthologues can be 767 to 1,136 amino acid-long) low complexity region (LCR) at the C-termini. Falafel fragments used in this study are indicated below. (b) In vitro binding of GST-tagged CENP-C with IVTTexpressed ${ }^{35} \mathrm{~S}$-Met-labelled Falafel but not with labelled R2 or PP4c. (c) Confocal microscopy of interphase D.Mel-2 cells showing nuclear and centromeric enrichment of Falafel. Magnified images below show co-localization of Falafel with the centromeric protein CENP-A/CID. Scale bar, $5 \mu \mathrm{m}$. (d) In vitro binding of GST-tagged $\mathrm{N}$-terminal (Flf| ${ }^{\mathrm{N}}$, see $\mathbf{a}$ ), (but not Middle and $\mathrm{C}$-terminal Flf| $\mathrm{I}^{\mathrm{M}}$ and $\mathrm{FIfl}^{\mathrm{C}}$, see $\mathbf{a}$ ) fragment of Falafel with ${ }^{35} \mathrm{~S}$-Met-labelled full-length $(\mathrm{fl})$ and $\mathrm{C}$-terminal part $\left(\mathrm{C}^{\prime}\right)$ but not with $\mathrm{N}$-terminal part $\left(\mathrm{N}^{\prime}\right)$ of CENP-C. (e) Identification of the Falafel Binding Domain (FBD/fragment C9), a 92-amino acid-long region of the $\mathrm{C}$-terminal part of CENP-C that can bind $\mathrm{FIfl}^{\mathrm{N}}$ in vitro. $\mathrm{CEN}$ indicates the centromeric localization motif ${ }^{58}$. ${ }^{\text {*' }}$ indicates globin from the reticulocyte lysate. (f) The EVH1 domain-containing GST-tagged Flf| ${ }^{\mathrm{N}}$ (aa 1-361) and its truncated form Flfl ${ }^{1-168}$ (aa 1-168) specifically bind to ${ }^{35} \mathrm{~S}-\mathrm{Met}-$ labelled CENP-C $\mathrm{CBD}^{\mathrm{FBD}}$ in vitro. In contrast FIfl ${ }^{169-361}$ (aa 169-361), the EVH1-lacking part of Flfl ${ }^{\mathrm{N}}$, which includes only an Smk-1 domain, cannot interact with ${ }^{35}$ S-CENP-C CBD. ' ${ }^{\prime \prime \prime}$ indicates globin from the reticulocyte lysate. (g) Western blots revealing that the entire PP4 complex is co-precipitated with

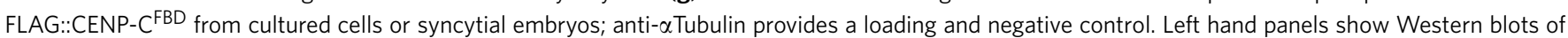
cultured cells expressing FLAG only (1) or FLAG::CENP-CFBD (2). Right hand panels show Western blots of syncytial embryo proteins purified on immobilized GST::CENP-C CBD. GST only serves as a negative control. Coomassie-stained gels demonstrate the loading of the bait proteins. 
Table 1 | Falafel-interacting proteins in D.Mel-2 cells.

Protein A::Falafel affinity purification

\begin{tabular}{lccrc}
\hline$\#$ & FlyBase CG & Protein & Score & Coverage (\%) \\
\hline 1 & 9351 & Falafel (bait) & 11,959 & 26 \\
2 & 31258 & CENP-C & 1,178 & 13 \\
3 & 42389 & CG42389 & 1,124 & 10 \\
4 & 32505 & PP4c & 872 & 27 \\
5 & 2890 & R2 & 316 & 7 \\
\hline
\end{tabular}

AP-MS, affinity purification-coupled mass spectrometry.

AP-MS reveals protein A::Falafel pulling down centromeric protein CENP-C as well as R2 and PP4c, subunits of PP4, from D.Mel-2 cells with good Mascot scores and sequence

representation (coverage).

Table 2 | CENP-C-interacting proteins in D.Mel-2 cells.

CENP-C::protein A affinity purification

\begin{tabular}{lcccc}
\hline \# & FlyBase CG & Protein & Score & Coverage (\%) \\
\hline 1 & 31258 & CENP-C (bait) & 6,141 & 31 \\
2 & 9351 & Falafel & 705 & 16 \\
3 & 32505 & PP4c & 632 & 28 \\
4 & 2890 & R2 & 621 & 23 \\
5 & 17870 & $14-3-3 z e t a$ & 268 & 18 \\
6 & 31196 & 14-3-3epsilon & 239 & 24 \\
7 & 13329 & CENP-A/CID & 184 & 12 \\
8 & 4817 & SSRP1 (FACT complex) & 98 & 3 \\
9 & 10223 & Topoisomerase2 & 86 & 1 \\
10 & 1828 & Dre4 (FACT complex) & 53 & 1
\end{tabular}

AP-MS, affinity purification-coupled mass spectrometry.

AP-MS of CENP-C::protein A reveals all three subunits of PP4 interacting with CENP-C in D.Mel-2 cells.

CENP-C, we employed an in vitro binding assay and found that the carboxy-terminal part of CENP-C specifically binds the amino-terminal part of Flfl (Fig. 1d, Supplementary Fig. 1b), which contains an EVH1 domain, a member of the PH-like superfamily (residues 1-102) and an Smk-1 domain (residues 169-361) separated by a short inter-domain region (residues 103168; Fig. 1a). Subsequently, we determined that a 92 -amino acid (aa)-long fragment within CENP-C (the Flfl Binding Domain (FBD); CENP-C residues 1002-1093) and the first 168 aa of Flfl $\left(\mathrm{Flfl}^{1-168}\right.$ ) were sufficient to support this interaction (Fig. 1e,f). Finally, by using recombinant CENP-C ${ }^{\mathrm{FBD}}$ and Flf ${ }^{1-168}$ expressed in bacteria and purified to homogeneity, we demonstrated that the two protein fragments can form a stable stoichiometric complex in vitro confirming the direct and suggesting a phosphorylation-independent interaction between them (Supplementary Fig. 1c).

Just as we could use full-length CENP-C expressed in D.Mel-2 cells as an affinity bait to purify the PP4 holoenzyme (Table 2), we could achieve the same purification using FLAG::CENP-C ${ }^{\mathrm{FBD}}$ (Fig. 1g). Moreover, all three subunits of PP4 could be successfully co-purified from Drosophila syncytial embryo extracts, when recombinant GST::CENP- $\mathrm{C}^{\mathrm{FBD}}$ protein was used as a bait (Fig. 1g), suggesting that CENP-C $\mathrm{C}^{\mathrm{BD}}$ is sufficient for the binding of the PP4 holoenzyme. In accord with these findings, CENP-C co-purified with protein A::Flfl ${ }^{1-168}$ from cultured cells (Supplementary Table 3), but not with protein A::Flfl ${ }^{169-973}$ (Supplementary Table 4). Using indirect IF we found that, similar to the endogenous protein (Fig. 1c), both FLAG-tagged Flfl and Flf ${ }^{1-168}$ localize to centromeres throughout the cell cycle (Supplementary Fig. 1d). By contrast, FLAG::Flf1 ${ }^{169-973}$ was completely excluded from centromeres (data not shown). This strongly suggests that the EVH1 domain within Flfl $^{1-168}$ is both necessary and sufficient to target Flfl to CENP-C and so to centromeres.

Flfl-interacting motif of CENP-C is an atypical EVH1 ligand. We asked whether the FBD of CENP-C might have features in common with known EVH1 ligands that contain high and repetitive proline content ${ }^{24}$. Therefore to more precisely define the interaction site, we probed an array of overlapping 20 aa peptides covering the entire CENP-C ${ }^{\mathrm{FBD}}$ fragment with recombinant Flf ${ }^{1-168}$. This identified a 19 aa sequence located in the middle of the FBD (CENP-C residues 1048-1066), which strongly interacted with Flf ${ }^{1-168}$ that we termed Flfl-interacting motif (FIM; Fig. 2a). We then tested the functional importance of this sequence by carrying out in vitro binding assays, which showed that the deletion of the FIM from CENP-C ${ }^{\mathrm{FBD}}$ prevented its interaction with ${ }^{35} \mathrm{~S}$-Met-labelled Flf ${ }^{1-168}$ (Fig. 2b). Although both the FIM deletion mutant of full-length CENP-C (FLAG:::CENP-C ${ }^{\triangle \mathrm{FIM}}$ ) and the wild-type protein (FLAG::CENP$\mathrm{C}^{\mathrm{WT}}$ ) localized to centromeres equally well, the FLAG::CENP$\mathrm{C}^{\Delta \mathrm{FIM}}$ protein was unable to interact with full-length Flfl or Flf1 ${ }^{1-168}$ in co-immunoprecipitation experiments (Fig. 2c) or with any of the PP4 subunits as indicated by proteomics (Supplementary Tables 5 and 6). Thus the FIM appeared to be indispensable for the complex formation within the context of full-length CENP-C protein. Finally we verified the role of FIM in the recruitment of Flfl-PP4 to centromeres. We found that FLAG::Flfl ${ }^{1-168}$ localized to centromeres when endogenous CENP-C was replaced with green fluorescent protein::CENP$\mathrm{C}^{\mathrm{WT}}$ (GFP::CENP-C $\mathrm{CT}^{\mathrm{WT}}$ ), but not at all when replaced with GFP::CENP-C ${ }^{\triangle F I M}$ (Fig. 2d and Supplementary Fig. 1e). Thus a 19-aa-long segment of CENP-C, the FIM, is crucial for the recruitment of Flfl and hence PP4 to centromeres.

As the FIM did not show any particular enrichment for proline residues characteristic of EVH1 ligands, we decided to define individual residues within this sequence that were important for the interaction. We found that substitution mutants at four adjacent sites within the 19-mer, 1057-Phe-Lys-Lys-Pro-1060 (FKKP), disrupted this binding suggesting their potential importance in making direct contact between the two proteins (Fig. 2e). The phenylalanine and proline residues appear absolutely critical for this interaction, while some variation in the identity of the intervening residues may be tolerated.

Conserved structure of the EVH1 domain of Flfl. To better understand the molecular basis for the Flfl-CENP-C interaction, we co-crystallized an amino-terminal 122-aa-long fragment of Flfl containing the EVH1 domain (Flfl ${ }^{1-122}$ ) and the CENP-C ${ }^{\mathrm{FIM}}$ peptide and solved the structure by molecular replacement to $1.5 \AA$ resolution as described in Methods. Crystallographic statistics and representative electron density are provided in Table 3 and Supplementary Fig. 2a, respectively. The final model comprises residues 4-114 of Flfl and 1055-1065 of CENP-C. We found that the Flfl ${ }^{1-122}$ fragment is composed of a seven-stranded $\beta$ barrel capped by a C-terminal $\alpha$-helix (Fig. 3a). Two concave surfaces are formed by the outside of each $\beta$ sheet, one of which (strands $\beta 1, \beta 2, \beta 5, \beta 6$ and $\beta 7$; Fig. 3a) forms the peptide-binding groove with contributions from an inter-strand loop (residues 66-69). The CENP-C peptide can be unambiguously identified as bound into that groove (Supplementary Fig. 2b). Although the structure of Flfl $^{1-122}$ slightly deviates from the canonical EVH1 domains (Supplementary Fig. 2c), three-dimensional searches using the DALI server ${ }^{25}$ showed several proteins in the EVH1 family $^{23}$ as close structural homologues. The EVH1 domain from 
a

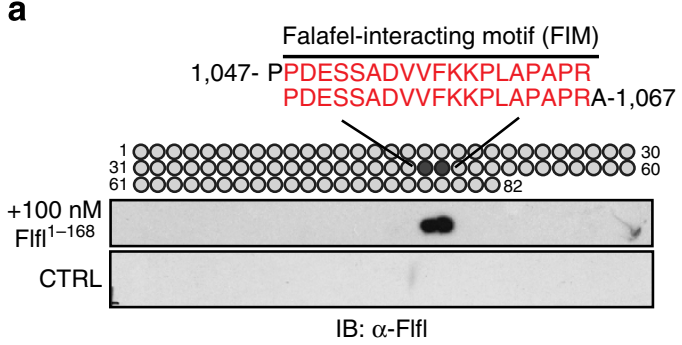

b

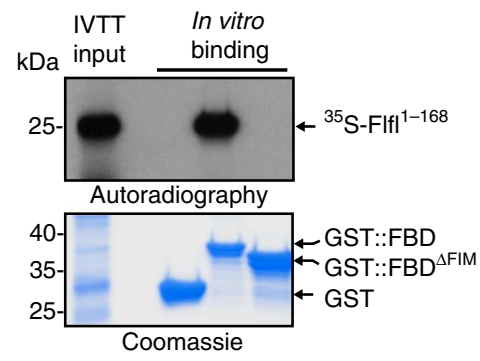

e

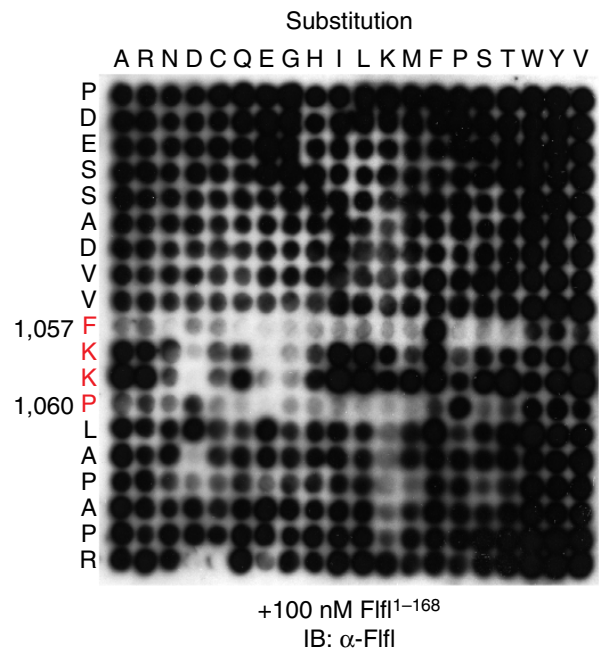

C

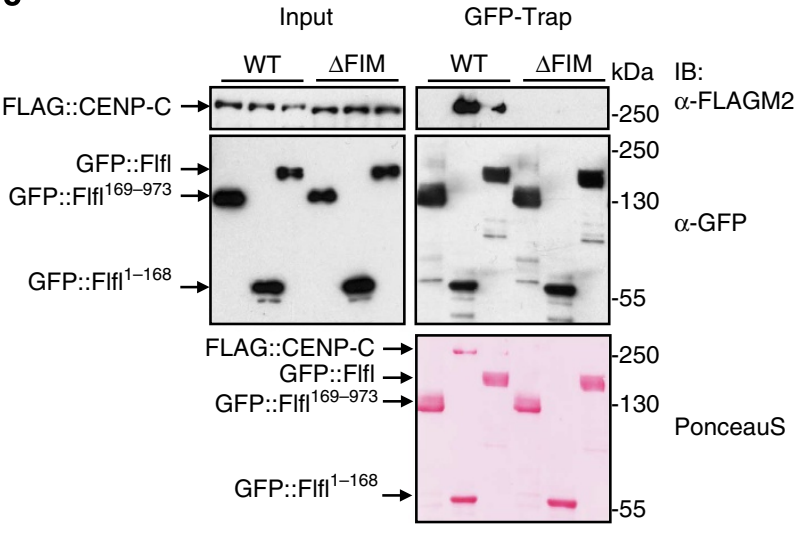

d

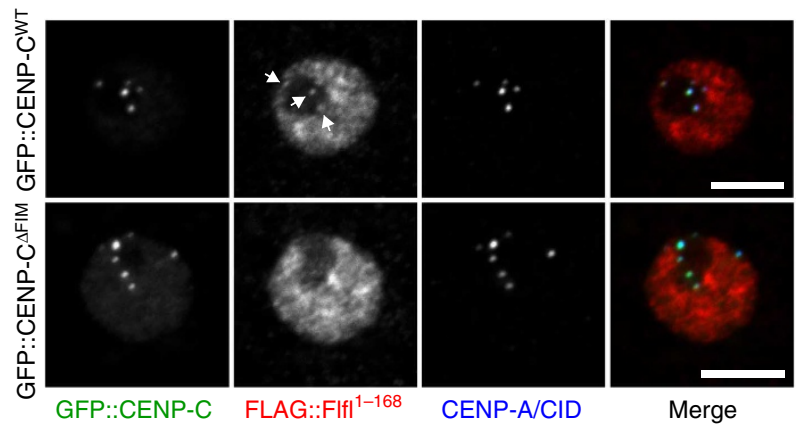

Figure 2 | CENP-C's FIM motif is crucial for Falafel binding and recruitment to the centromere. (a) Peptide array: Flf|'-168 binds to two 20-mer peptides in CENP-C $C^{\text {FBD }}$ identifying the 19-amino acid-long Falafel-interacting motif (FIM). (b) ${ }^{35}$ S-Met-labelled FIfl ${ }^{1-168}$ is able to show in vitro binding to GST-tagged wild-type FBD (GST::FBD) but not to the FIM-deleted FBD (GST::FBD ${ }^{\Delta F I M}$ ). (c) GFP-Trap purification of full-length Falafel (GFP::FIfI) or its 1-168 amino acid fragment (GFP::FIf-168) co-precipitates FLAG-tagged CENP-C (FLAG::CENP-C). This interaction is lost following deletion of the FIM ( $\triangle$ FIM). GFP:::FIfl ${ }^{169-973}$ provides a negative control. Ponceau S staining assesses loading. (d) D.Mel-2 cells depleted of endogenous CENP-C and co-expressing FLAG::FIfl'168 with either GFP::CENP-CWT or GFP::CENP-C ${ }^{\triangle F I M}$. In the absence of FIM, FIfl'-168 no longer localizes to the centromere. Arrows indicate centromeric FLAG::FIfI ${ }^{1-168}$ signals. Scale bars, $5 \mu \mathrm{m}$. See also Supplementary Fig. 1e. (e) Peptide substitution array indicating that the sequence ${ }^{1057}$ Phe-Lys-Lys-Pro ${ }^{1060}$ within CENP-C is critical for Flfl ${ }^{1-168}$ binding in vitro.

MENA $^{26}$ appears most closely related structurally (root-meansquare deviation $2.2 \AA$ over $113 \mathrm{C} \alpha$ positions; $Z$-score $=13.8$ ). The binding site lies in a highly conserved groove on the surface of the protein (Fig. 3b,c) burying $1,700 \AA^{2}$ of the total $6,700 \AA^{2}$ surface of Flfl ${ }^{1-122}$ and corresponds to the surface responsible for binding proline-rich sequences in other members of the EVH1 family ${ }^{27}$. The residues within the EVH1 domain, which are involved in binding to CENP-C ${ }^{\mathrm{FIM}}$, are highly conserved in the R3 subunits of PP4 from a very wide range of other organisms (Supplementary Fig. 2d).

Residues $1055-1065$ of the CENP-C ${ }^{\text {FIM }}$ peptide are well defined in the electron density, and include FKKP motif of the residues predicted to interact with the Flfl ${ }^{1-122}$ by peptide array analysis (Fig. 2e). The peptide backbone adopts a left-handed helical conformation similar to the polyproline II (PPII) helix ${ }^{28}$. This arrangement is mainly stabilized by the establishment of hydrogen bonding and van der Waals interaction between Pro1060 and Trp20. The twofold pseudo-symmetry displayed by the PPII helix enables bidirectional ligand binding often observed in polyproline recognition motifs such as the $\mathrm{SH} 3$ domain $^{29,30}$. Additional residues flanking the PPII sequence provide directional specificity. In our structure CENP-C's Phe1057 and Pro1060 provide the principle specificity and directionality of binding (Fig. 3d and Supplementary Fig. 2e; see also the legend for Supplementary Fig. 2e). EVH1 domain ligand selectivity is dependent on which family the domain belongs to 27 . Class I EVH1 domains, as found in the Ena/VASP proteins recognize FPPPP sequences, while Class II domains, exemplified 


\section{Table 3 | Data collection and refinement statistics (molecular replacement).}

Falafel (1-122)_CENP-C (FIM)

\begin{tabular}{lc}
\hline Data collection & \\
Space group & $\mathrm{P} 6_{1}$ \\
Cell dimensions & \\
$a, b, c(\AA)$ & $67.75,67.75,53.37$ \\
$\alpha, \beta, \gamma\left({ }^{\circ}\right)$ & $90,90,120$ \\
Resolution $(\AA)$ & $58.68-1.50(1.55-1.50)$ \\
$R_{\text {sym }}$ or $R_{\text {merge }}$ & $0.03(0.39)$ \\
$V / \sigma /$ & $11.72(1.84)$ \\
Completeness $(\%)$ & $99.70(98.19)$ \\
Redundancy & $6.7(6.45)$ \\
& \\
Refinement & \\
Resolution $(\AA)$ & $58.68-1.50$ \\
No. reflections & 22,313 \\
$R_{\text {work }} / R_{\text {free }}$ & $(0.19) / 0.17(0.26)$ \\
No. atoms & 1,061 \\
Protein & 971 \\
Ligand/ion & 5 \\
Water & 85 \\
B-factors & 31.5 \\
Protein & 30.6 \\
Ligand/ion & 44.6 \\
Water & 41.6 \\
R.m.s deviations: & \\
Bond lengths $(\AA)$ & 0.009 \\
Bond angles $\left({ }^{\circ}\right)$ & 1.17 \\
& \\
\hline FIM, Falafel-interacting motif; r.m.s, root mean square. & \\
Statistics for the highest-resolution shell are shown in parentheses. & \\
&
\end{tabular}

by Homer/Vesl, bind a PPxxF motif. Class III domains, found uniquely in WASP proteins are specific for LPPPEP. The ligands for Class IV domains, also known as Spred domains, are unknown. A structural study has suggested that the Spred-1 EVH1 domain may preferentially bind low proline content ligands due to a narrowed peptide-binding channel with slight displacement of the conserved tryptophan and associated strand $\beta 2$ (ref. 31). However, in our structure this element more closely resembles the canonical EVH1 fold. Although the FKKP motif recognized by Flfl closely resembles the inverted PPxxF sequence bound by Homer, the mGluR-Homer crystal structure shows an unusual peptide conformation, in which the peptide backbone arches away from the EVH1 surface to place the terminal phenylalanine in a unique binding pocket ${ }^{32}$. In our structure, the FIM is bound in the reverse orientation to that of the mGluR peptide, placing the phenylalanine in a roughly similar location. However, the peptide is bound to Flfl in a more classical configuration that resembles Class I and Class II ligands by maintaining PPII configuration for its full length. We suggest that Flfl-FIM interaction constitutes a novel mode of EVH1 binding in which a low proline content ligand is recognized in a PPII conformation.

PP4 is necessary for the integrity of mitotic centromere. Having defined the interaction site between Flfl and CENP-C, we then wished to assess its biological significance. To this end we first depleted cells of Flfl and recorded the behaviour of centromeres throughout the cell cycle. We did not observe any consequences of Flfl depletion in interphase cells. However, during mitosis a proportion of CENP-C became displaced from centromeres and accumulated on the spindle microtubules or around the spindle poles. In contrast, CENP-C was entirely restricted to centromeres in control cells (kan RNAi versus flfl RNAi; top two panels in Fig. 4a; quantitation in Fig. 4b). CENP-C serves a fundamental role at the centromere both as a component of the centromere itself and as a partner of the kinetochore-associated Mis12 complex $^{21,22}$. We therefore investigated whether CENP-C's centromeric displacement also affected the mitotic localization of any of the core kinetochore proteins. We found that while the centromeric protein, CENP-A, remained associated with the centromere, the displaced CENP-C was accompanied by all core kinetochore components, exemplified by Mis12, Nsl1 and Spc105 (Supplementary Fig. 3).

To address whether the direct binding of Flfl to CENP-C was responsible for maintaining centromere integrity during mitosis, we determined the consequences of specifically disrupting the CENP-C-Flfl interaction. To this end we substituted endogenous CENP-C with FLAG-tagged CENP-C deleted for the FIM (FLAG::CENP-C ${ }^{\Delta F I M}$ ). This not only led to the removal of Flfl from interphase centromeres, but also resulted in the displacement of CENP-C $\triangle$ FIM from centromeres in mitosis (Fig. 4a,c). Thus when CENP-C fails to recruit Flfl, the integrity of the mitotic centromere is compromised in a manner similar to that occurring following Flfl depletion.

To address whether the mitotic centromere association of CENP-C requires PP4's catalytic activity, we first depleted its catalytic subunit PP4c. This resulted in partial CENP-C displacement from centromeres in mitotic cells (Fig. 4b), similar to the effects of Flfl depletion. However, we could not rule out the possibility that the CENP-C mislocalization phenotype represented loss of a structural function for the PP4c subunit and so we decided to develop a catalytically inactive form of this phosphatase. To do this we first needed to identify changes in the phospho-modifications of proteins associated with loss of PP4. Interestingly, we noticed that on PP4c depletion, Flfl remained hyper phosphorylated and migrated slower in a bandshift assay (Fig. 5a). We also found that the FLAG-tagged FBD of CENP-C displayed lambda phosphatase ( $\lambda$-PPase) sensitive bands (Fig. 5b) of higher electrophoretic mobility after depletion of either Flfl, PP4c or in the presence of phosphatase inhibitor, okadaic acid (Fig. 5c). These observations suggest that both Flfl and CENP-C are novel substrates of PP4, although we cannot rule out the possibility of the indirect inhibition of some secondary phosphatase on PP4 knockdown. In addition, these findings provided us with a simple assay for assessing the catalytic activity of PP4c. To design a catalytically inactive PP4c, we first aligned the primary sequences of the catalytic subunits of PP2Ac/mts and PP4c, which identified highly conserved residues in the active site regions $^{33}$ (Supplementary Fig. 4a). We then engineered a transgene with the aa substitutions, D85N and H115N, which should render the phosphatase catalytically inactive. Consistent with the loss of enzymatic activity, D.Mel-2 cells expressing this phosphatase-dead (PhD) mutant of PP4c in the absence of its endogenous counterpart no longer displayed a Flfl doublet on immunoblots (IBs) but only the slower migrating, phosphorylated form of the protein (Fig. 5d). This phosphatase-dead counterpart of $\mathrm{PP} 4 \mathrm{c}\left(\mathrm{PP} 4 \mathrm{c}^{\mathrm{PhD}}\right)$ could interact with both $\mathrm{R} 2$ and Flfl (Supplementary Fig. 4b), confirming the structural integrity of the inactive trimeric phosphatase. We then expressed PP4c $\mathrm{C}^{\mathrm{WT}}$ or $\mathrm{PP} 4 \mathrm{c}^{\mathrm{PhD}}$ in D.Mel-2 cells lacking endogenous PP4c (Supplementary Fig. 4c) and assessed their progression through mitosis. The loss of PP4 catalytic activity resulted in CENP-C displacement from the centromeres (Fig. $4 \mathrm{a}$, bottom panels) to virtually the same extent as both Flfl and PP4c depletions (compare Fig. 4d with Fig. 4b and c). Thus, centromere integrity during mitosis requires the localized delivery of the catalytic subunit to the centromere mediated by the interactions of PP4's $\mathrm{R} 3$ regulatory subunit, Flfl and the centromeric protein CENP-C. 
a
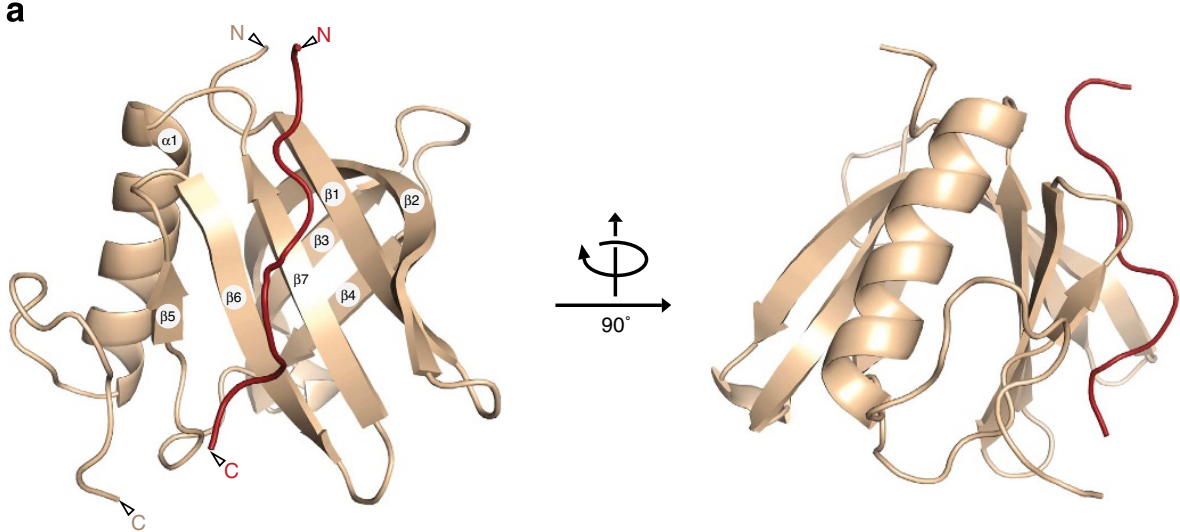

b

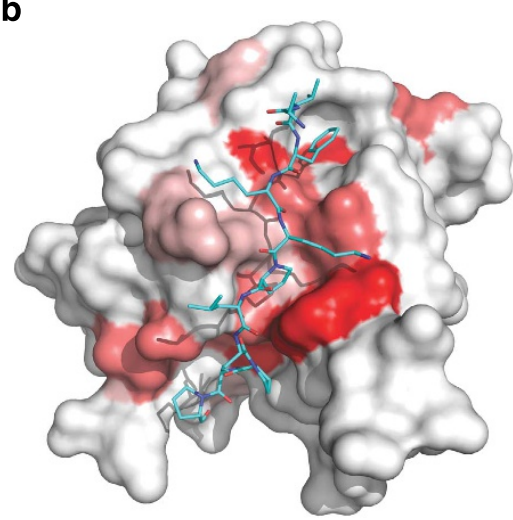

d

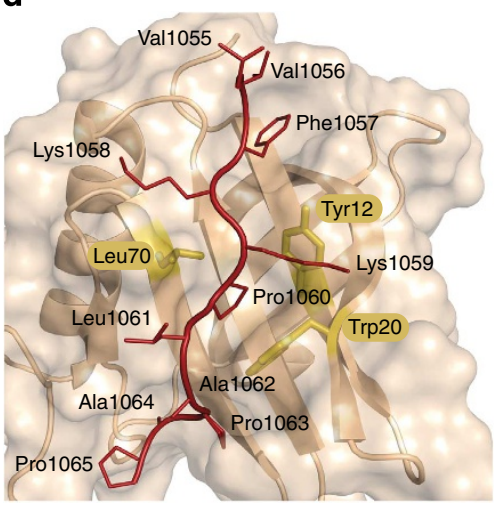

C

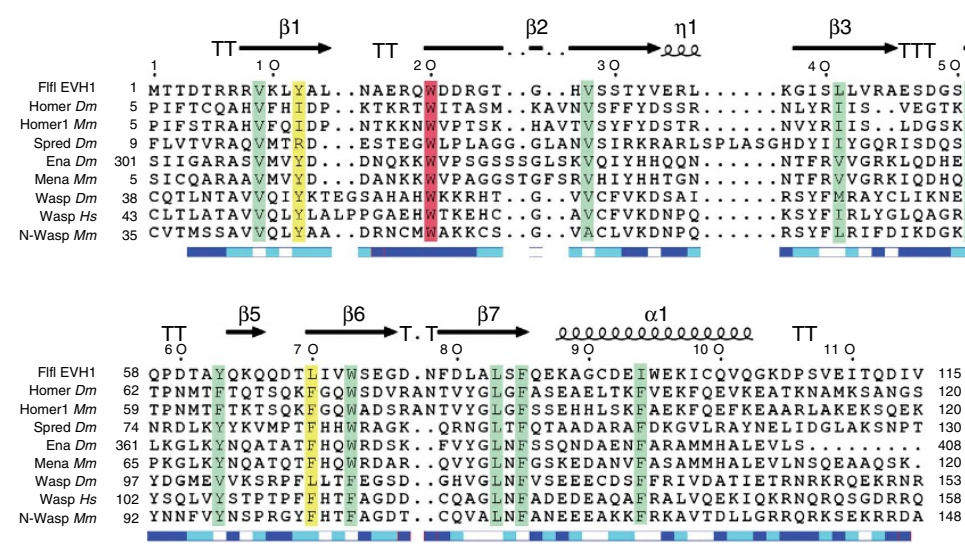

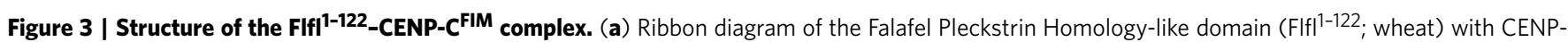
C FIM peptide (red) in two different orientations. (b) Representation of Flfl'-122 surface conservation coloured from red (highly conserved) to white (nonconserved). The deepest red 'shelf' lying in the middle of Flf1 ${ }^{1-122}$ is due to the highly conserved Trp20. (c) Sequence alignment of EVH1 domains from Homer, Spred, Ena, Mena, Wasp and N-Wasp. Species are Mm (Mouse), Hs (Human) and Dm (Drosophila). Secondary structural elements of the FIfl'-122 are represented by arrows ( $\beta$ strands), squiggles ( $\alpha$ helices) and T (turns). Highly conserved residues are coloured in green. The invariant tryptophan is coloured in red and residues involved in proline stacking in EVH1 but not F|f| $\left.\right|^{1-122}$ in yellow. The relative accessibility of each residue is rendered as blue-coloured boxes located at the last line of each block. The blue scale is set as follows: blue, accessible; cyan, intermediate and white, buried. The Flfl'-122 deviates from the canonical EVH1 domain; a conserved phenylalanine (Phe77 in 1EVH) is replaced by leucine (Leu70) and the side chain of a conserved

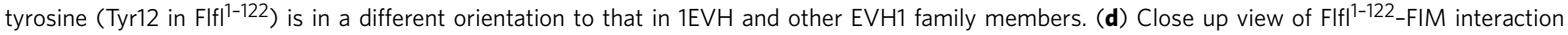
site. CENP-C residues have been labelled and three critical residues from the $\mathrm{Flfl}^{1-122}$ ligand recognition site are highlighted in yellow. Phe1057 occupies a hydrophobic pocket composed largely of the methylene groups of a series of hydrophilic amino acid side chains, while Pro1060 of CENP-C is sandwiched between Leu70 and the highly conserved Trp20.

\section{Discussion}

Studies of protein phosphatases have been limited by restricted knowledge of either the mechanisms that regulate their specificity or the identity of the protein kinases they oppose. Moreover, the fact that most protein phosphatases are multimeric complexes, in which regulatory subunits deliver stability, localization and substrate recognition activities to the catalytic subunits, has limited the number of inhibitory compounds that have been 
a

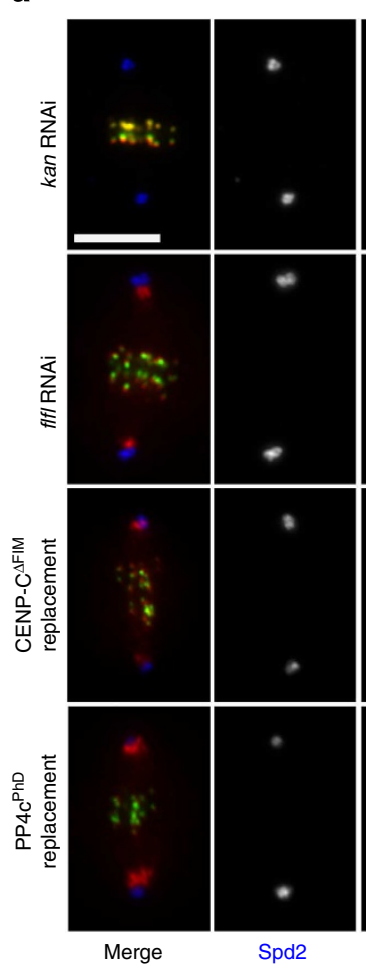

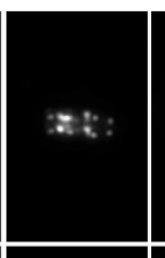
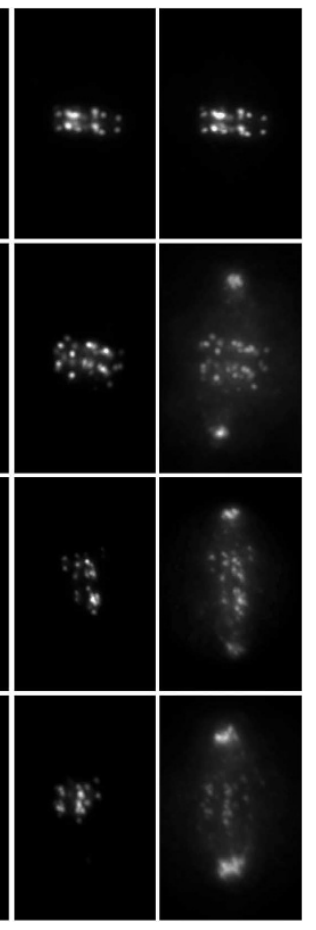

CENP-A/CID
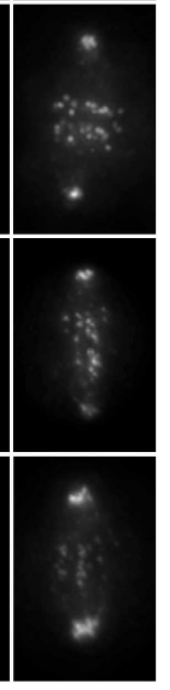

CENP-C b

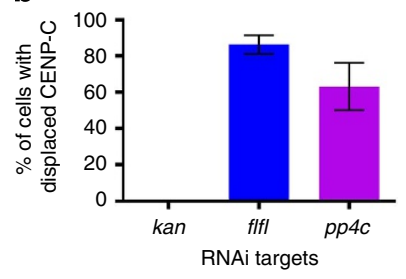

C

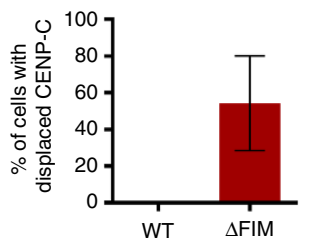

CENP-C transgenes expressed in cenp-c $c^{5^{\prime} U T R}$ RNAi background

d

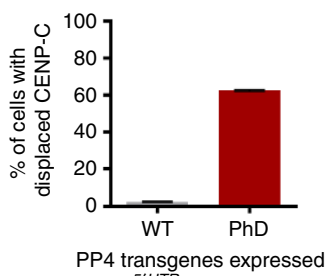

in $p p 4 c^{5^{\prime} U T R}$ RNAi background

Figure 4 | Presence and catalytic activity of PP4 are required to regulate mitotic centromere integrity. (a) A proportion of CENP-C is mislocalized from the centromeres and accumulated along the spindle and spindle poles in flfl-depleted mitotic cells. kan RNAi is used as a negative control. The same phenotype is observed after replacement of endogenous CENP-C with FLAG::CENP-C $\triangle$ FIM or replacement of endogenous PP4C with FLAG::PP4 ${ }^{\text {PhD }}$. Scale bar, $5 \mu \mathrm{m}$. Spd2, centrosome marker; CENP-A/CID, centromere marker. (b) Proportion of mitotic cells showing CENP-C mislocalization on kan (control), fIfl or pp4c depletions. (c) FLAG::CENP-C ${ }^{\Delta F I M}$ cannot complement centromeric function of depleted endogenous CENP-C. (d) FLAG::PP4c WT can fully rescue CENP-C displacement resulting from depletion of endogenous PP4c, whereas the phosphatase-dead form (FLAG::PP4c ${ }^{\text {PhD }}$ ) cannot. Bars represent s.d. in all three graphs; $n>50$ for each condition.

developed against them ${ }^{1,34,35}$. Together, this has led to a significant delay in our understanding of how exactly phosphorylation regulates multiple cellular processes.

We have developed an interest in PP4 as a newly emerged regulator of cell cycle progression ${ }^{8,9}$. PP4 is a member of the PP2A family of Ser/Thr phosphoprotein phosphatases and as in the case of PP2A, the common form of the holoenzyme comprises a catalytic and two regulatory subunits. We were specifically led to study potential roles of Flfl, the R3 subunit of PP4 in Drosophila, because of the involvement of R3 subunits in a variety of cellular processes ${ }^{3,11}$ including the cell cycle ${ }^{16}$. The human R3 $\beta$ subunit SMEK2, for example, participates in regulation of S-phase progression and behaves as a chromatin protein phosphorylated by the cyclin-dependent kinases ${ }^{36}$. In addition, R3 subunits of PP4 influence cell cycle progression through involvement in DNA repair pathways 6,7 . Our present finding of a functional interaction between Flfl and CENP-C directly illustrates the role played by the R3 subunit in targeting the PP4 to the centromere to regulate its structure and function.

Several previous studies have implicated R3 as the targeting subunit of PP4 (see introduction). This regulatory subunit is well conserved from yeast to human and has an EVH1 domain and a Smk-1/DUF625 domain occupying the N-terminal part of the protein (Fig. 1a). This part of the molecule appears important in all of its targeting interactions described to date: the Smk-1/ DUF625 domain of mammalian R3 $\alpha$ interacts with the PP4 substrate Par3 in neuronal differentiation ${ }^{17}$; the EVH1 domain of yeast R3 interacts with the PP4 substrate Mth1 (see ref. 18) and the EVH1 (formerly RanBD) domain of Drosophila R3, Flfl, binds Mira to regulate asymmetric division of neuroblasts ${ }^{19}$. We now show that the EVH1 domain of Flfl also directly interacts with the key centromeric protein, CENP-C.

EVH1 domains are structurally related to $\mathrm{PH}$ domains but generally bind to proline-rich amino-acid sequences rather than phospholipids. Our study provides the first analysis of the interaction between an $\mathrm{R} 3$ regulatory subunit and its target at atomic resolution that together with in vitro and in vivo binding assays unequivocally confirms complex formation between these proteins. This mode of targeting PP4 to its substrate(s) appears very different to other Ser/Thr protein phosphatases such as PP1 and $\mathrm{PP} 2 \mathrm{~A}$, in which the variable regulatory subunits often form a contiguous substrate recognition surface with the conserved catalytic subunit ${ }^{37}$. The R3 regulatory subunits of PP4 by contrast appear to rely on a flexibly linked EVH1 domain for substrate recruitment, which then presumably places the catalytic subunit proximal to the target residue(s). Analysis of the crystal structure shows that the interaction takes place in the groove that forms within the EVH1-like domain of Flfl. This domain deviates from the canonical EVH1 domain in that a conserved phenylalanine (Phe77 in 1EVH) is replaced by leucine (Leu70) and the side chain of a conserved tyrosine (Tyr12 in Flfl ${ }^{1-122}$ ) is in a different orientation to that in other EVH1 family members (Fig. 3c and Supplementary Fig. 2c). Nevertheless, the 3D organization of this part of Flfl shows close structural homology with other EVH1 domains. Moreover, EVH1 domains present in amino termini of R3 subunits of PP4 phosphatases are highly conserved at their primary sequence, suggesting that their mode of binding to ligands will also be conserved (Supplementary Fig. 2d). 
a

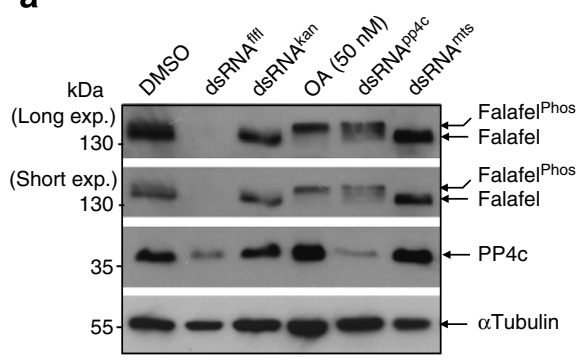

C

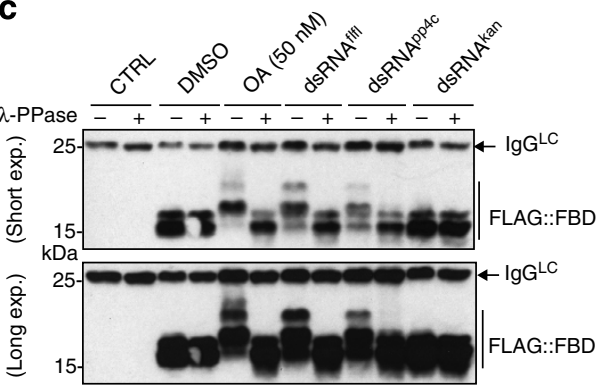

b

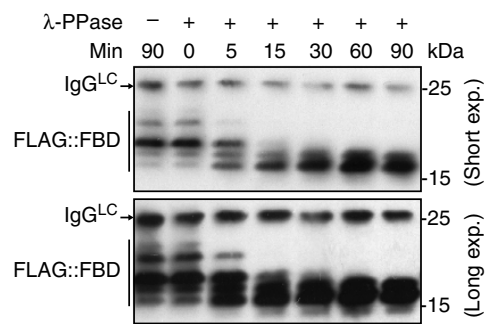

d

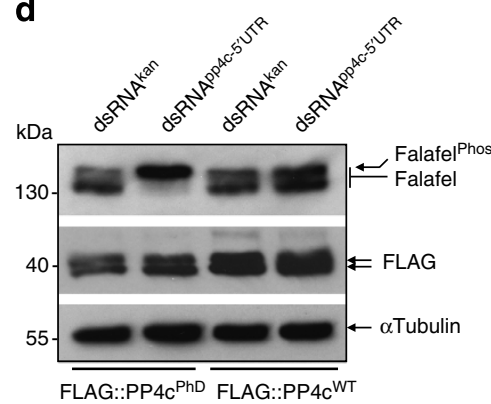

e

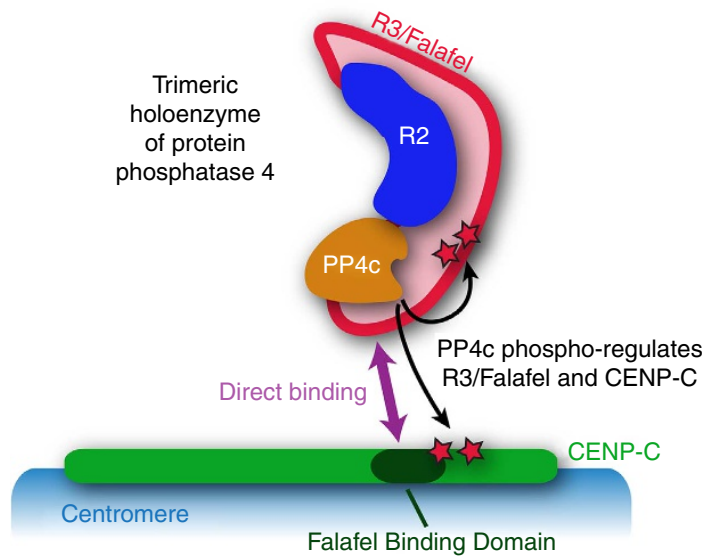

Figure 5 | PP4 phosphoregulates Falafel and CENP-C. (a) Treatment of D.Mel-2 cells with interfering ds flfl RNA leads to reduction of both Falafel and PP4c, suggesting that the depletion of a regulatory subunit of PP4 results in the destabilization of the catalytic subunit (as observed also for PP2A (ref. 8)). Falafel migrates as a doublet. Treatment with $50 \mathrm{nM}$ okadaic acid (OA) indicates that the upper band represents a phosphorylated form. On depletion of PP4c (dsRNA ${ }^{p p 4 c}$ ) but not PP2Ac (dsRNA ${ }^{m t s}$ ) the phosphorylated form of Falafel predominates, suggesting that Falafel is a novel PP4 substrate. $\alpha$ Tubulin is loading control. (b) The CENP-C CBD fragment is phosphorylated in vivo. FLAG::FBD undergoes shifts in its electrophoretic mobility following treatment in vitro with $\lambda$-PPase. Samples were run on Phos-tag SDS-PAGE followed by immunoblotting. (c) Phospho status of CENP-C ${ }^{F B D}$ depends on the presence of PP4. Extracts of cells expressing FLAG::FBD treated with nothing (control), DMSO, $50 \mathrm{nM}$ okadaic acid (OA) and interfering dsRNAs targeted against flfl (dsRNA $\left.A^{f f f}\right), p p 4 c\left(d s R N A^{p p 4 c}\right.$ ) and control (dsRNA ${ }^{k a n}$ ). Phosphorylated forms are seen following okadaic acid treatment and following depletion of Falafel or PP4c, indicating that the PP4 holoenzyme is required to maintain the dephosphorylation status of FLAG::FBD in vivo. (d) Electrophoretic mobility

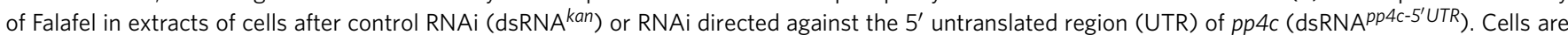
expressing either the transgenic FLAG-tagged phosphatase-dead variant of PP4c (FLAG::PP4c ${ }^{\text {PhD }}$ ) or its wild-type counterpart (FLAG::PP4c ${ }^{W T}$ ). Note that Falafel migrates as its phosphorylated form in the FLAG::PP4 $4 c^{\text {PhD }}$-expressing cell line, indicating that the PP4 catalytic activity is required for Falafel dephosphorylation in vivo. (e) A hypothetic model demonstrating that PP4 activity is localized at centromeres in Drosophila cells. Regulatory subunit 3, Falafel, directly interacts with the Falafel Binding Domain of CENP-C (violet arrow), which brings the trimeric holoenzyme of PP4 to centromeres. Centromeric PP4 activity is important for the integrity of mitotic centromeres and affects the phospho status of Falafel and CENP-C (highlighted as red stars).

Interestingly, unlike other EVH1 ligands, the segment of CENP-C that binds Flfl does not have an enriched and repetitive proline content. Within the 19 aa FIM of CENP-C, we identify a stretch of four aa of which Phe1057 and Pro1060 are key for specificity of binding. They also direct the orientation of binding within the EVH1 groove. This evokes a direct comparison with the crystal structure of the Homer EVH1 domain bound to an mGluR peptide that contains the reverse $\mathrm{PxxF}$ recognition motif ${ }^{32}$. It seems, however, that the Homer EVH1 domain might be more of an exception to the rule since the FxxP sequence in CENP-C appears to adopt a conformation extremely similar to the lefthanded PPII helix, which more typically interacts with the EVH1 domains. It is of future interest to examine the variations allowed at this interface in considering the targeting of PP4 to its multiple 
sites of action via its R3 subunit, and how the remainder of the R3 domain may participate in substrate binding.

Our results point to the functional importance of the interaction between the Flfl EVH1 domain and CENP-C in bringing the catalytic subunit $\mathrm{PP} 4 \mathrm{c}$ to centromeres. Failure to do this results in some loss of integrity of the centromere during mitosis that we demonstrate in several ways. First, cells depleted of Flfl exhibit displacement of CENP-C away from centromeres and towards the centrosome during mitosis, whereas localization of the centromeric histone CENP-A/CID remains unaffected. This specifically requires the interaction between Flfl and CENP$\mathrm{C}$ because the same phenotype is evoked when endogenous CENP-C is substituted by a CENP-C ${ }^{\Delta \text { FIM }}$ mutant, which does not bind Flfl. Two pieces of evidence suggest that Flfl's function in this context is to deliver protein dephosphorylation activity to centromeres: CENP-C also becomes displaced from centromeres during mitosis either following depletion of the PP4 catalytic subunit, PP4c, or when Phosphatase Dead PP4c is substituted for the endogenous wild-type protein.

CENP-C is not only a structural component of the centromere but it also provides a scaffold for kinetochore assembly and a hub for kinetochore regulation ${ }^{21,22,38}$. We have previously observed that mislocalization of CENP-C at the centrosome through other means results in mislocalization of kinetochore proteins ${ }^{21}$, just as we now observe following loss of PP4 activity from the centromere. The extensive phospho-modification of CENP-C represents a tremendous technical challenge to the unravelling of the precise patterns of protein phosphorylation and dephosphorylation that regulate its function. Genome-wide phospho-proteomics studies have previously found CENP-C to be heavily phosphorylated at multiple sites ${ }^{39,40}$, suggesting that it may be phosphorylated by multiple protein kinases. Our own analysis identifies at least 20 sites on CENP-C phosphorylated in vivo (David Glover lab, unpublished data). Although the direct roles of protein phosphatases in dephosphorylating these sites must first await the identification of the opposing protein kinases, it seems very likely that both multiple kinases and multiple phosphatases will be involved.

CENP-C together with CENP-A/CID and CAL1 forms a complex at the Drosophila centromere, and the three proteins show interdependency in their localization ${ }^{41}$. Our observations imply that in the absence of the centromeric function of PP4, the association of CENP-C with its other centromeric partners is weakened, either during loading or maintenance at centromeres, allowing its displacement towards spindle poles. While our findings implicate CENP-C as a putative PP4 substrate, it seems reasonable to assume that it is not the only centromere/ kinetochore protein dephosphorylated by PP4. Indeed it has been described, for example, that in human cells PP4 phosphoregulates Ndel1, the human orthologue of Drosophila $\mathrm{NudE}^{42}$, which is critical for the recruitment of dynein to kinetochores $^{43}$ and also regulates microtubule organization ${ }^{42,44}$. Another study finds the kinetochore component Dsn1 as a potential target of PP4 (see ref. 5). Thus dephosphorylation of alternative kinetochore substrates could also influence centromeric protein function.

The central finding of our study is that a variant of an EVH1like fold located in the amino-terminal part of Flfl, the R3 subunit of Drosophila PP4, is required to bind to a motif in the carboxyterminal part of CENP-C and so to target PP4 phosphatase activity to regulate centromeric structure (Fig. 5e). This opens the door not only for studies on the structure and function of PP4 but also on which centromeric or kinetochore proteins might be regulated by PP4 activity and about their exact roles in kinetochore biology and the regulation of cell cycle progression.

\section{Methods}

DNA constructs. Complementary DNA clones for PP4c (RE58406; CG32505, PP4-19c), R2 (LD28993; CG2890; PP4R2r) and Flfl (LD13350; CG9351, flfl/PP4R3) were obtained from the Drosophila Genomics Resource Centre. Full length, $N^{\prime}$ and $\mathrm{C}^{\prime}$ of CENP-C were made previously ${ }^{21}$. DNA encoding full-length CENP-C or its truncated forms (FBD (CENP-C $1002-1093 \mathrm{aa}), \mathrm{FBD}^{\Delta \mathrm{FIM}^{1}}\left(\mathrm{FBD}^{\Delta 47-65 \mathrm{aa}}\right)$ and CENP$\mathrm{C}^{1202-1411 \text { aa }}(\mathrm{C} 3)$ ), full-length subunits of PP4 (PP4c, R2 and Flfl) and truncated forms of Flfl (Flfl ${ }^{\mathrm{N}}$ (aa 1-361), Flfl ${ }^{\mathrm{M}}$ (aa 362-666), Flfl ${ }^{\mathrm{C}}$ (aa 667-973), Flfl ${ }^{1-168 a a}$ Flfl $^{169-361 a a}$ or Flfl $\left.{ }^{169-973 a a}\right)$ or PP4c (PP4c $\left.{ }^{1-50 a a}\right)$ were respectively cloned into pDONR221 using the Gateway System (Life Technologies). CENP-C $C^{\Delta 1048-1066 a a}$ (hereafter CENP-C ${ }^{\Delta \text { FIM }}$ ) or PP4 $c^{\text {D85NH115N }}$ (hereafter PP4 $4 c^{\mathrm{PhD}}$ as Phosphatase Dead) entry clones were created by standard mutagenesis using QuikChange II XL Site-Directed Mutagenesis Kit (Agilent Technologies). All entry clones were verified by DNA sequencing. Expression constructs were then made using the following destination vectors: pDEST15 (N-terminal GST fusion in Escherichia coli, Life Technologies), pDEST17 or pET-DEST42 (N- or C-terminal $6 \times$ His fusion in E. coli or in vitro transcription/translation; Life Technologies), pAFW and pAWF $(\mathrm{N}$ - or C-terminal $3 \times$ FLAG fusion in D.Mel-2 cells, Drosophila Gateway Vector Collection), pMT-PrA (N-terminal protein A fusion under the regulation of the copper-inducible Metallothionein A (CG9470) promoter in D.Mel-2 cells, in house), pMT-GFP (N-terminal eGFP-fusion in D.Mel-2 cells, in house) and pMAT-PrA-N/C (N- or C-terminal protein A fusion under the regulation of maternal $\alpha$ tubulin promoter in Drosophila embryos, in house). Conventional cloning was used to insert full-length CENP-C CDS into the pAc5.1_V5-ProtA vector (obtained from Paolo D'Avino, Department of Pathology, University of Cambridge) for constitutive expression with a protein A tag in D.Mel-2 cells ${ }^{21}$ His::TEV::Flfl ${ }^{1-168 a a}$, His::TEV::Flfl ${ }^{1-122 a a}$ (hereafter Flfl ${ }^{1-122}$ ) or His::TEV::CENP$\mathrm{C}^{\mathrm{FBD}}$ constructs were made by PCR amplification of the coding regions with a TEV protease cleavage site fused to their $5^{\prime}$ ends. The PCR products were inserted into the pETDuet-1 plasmid (Novagen) in frame with the N-terminal $6 \times$ His-tag (MCS1). DNA constructs for the coupled IVTT expression of full-length untagged PP4c, R2 or Flfl were made by conventional cloning: CDS were amplified by PCR and inserted into the T7 promoter-regulated pETDuet-1 plasmid (MCS2). T7 promoter-driven pDEST17/CENPC-fl, CENPC-N ${ }^{\prime}$ or CENPC- $\mathrm{C}^{\prime}$ constructs used in IVTT were made by the LR reaction. Linear DNA fragments used in IVTT encoding truncated forms of CENP-C-C' $\left(\mathrm{C} 1-\mathrm{C} 11\right.$, see Fig. 1e) or Flfl (Flfl ${ }^{1-168}$ ) were generated by PCR using appropriate primers to create the following configuration: T7-Kozak-ATG-gene-specific sequence-STOP codon. Oligonucleotide primers used in this study are listed in Supplementary Table 7.

Recombinant protein expression and purification. For crystallizations studies, His::TEV::Flfl ${ }^{1-122}$ was expressed in E. coli strain BL21 (DE3) RIL and purified to homogeneity as follows: cells were grown to $\mathrm{A} 600=0.6$ and expression was induced with $1 \mathrm{mM}$ isopropyl 1-thio- $\beta$-D-galactopyranoside overnight at $18^{\circ} \mathrm{C}$. Cells were lysed by sonication in buffer containing $150 \mathrm{mM} \mathrm{NaCl}, 50 \mathrm{mM}$ Tris-HCl, pH 8.0, 0.1 mM EDTA, 0.5 mM Tris(2-carboxyethyl)phosphine, complete protease inhibitor cocktail (Roche, 11873580001) and centrifuged at $34,000 \mathrm{~g}$ to pellet cell debris. The cleared lysate was loaded onto a $5 \mathrm{ml}$ HisTrap HP column (GE Healthcare) and eluted with a gradient of 0-250 mM imidazole. His::TEV was removed by adding TEV protease (in house) to the main Flfl ${ }^{1-122}$-containing fractions, which then were further purified by anion-exchange chromatography using a $5 \mathrm{ml}$ HiTrap Q Sepharose FF column (GE Healthcare) and eluted with a gradient of $0.15-1 \mathrm{M} \mathrm{NaCl}$. The final purification was performed using size exclusion chromatography in buffer containing $150 \mathrm{mM} \mathrm{NaCl}, 50 \mathrm{mM}$ Tris- $\mathrm{HCl}$, $\mathrm{pH}$ 8.0, $0.5 \mathrm{mM}$ Tris(2-carboxyethyl)phosphine. The purity of samples was analyzed by SDS-PAGE.

For other purposes, His- or GST-tagged proteins were expressed in Rosetta2(DE3)pLysS Singles (Novagen) E. coli strain as detailed above. GST-tagged proteins were affinity purified on Glutathione Sepharose $4 \mathrm{~b}$ resin (GE Healthcare) according to the manufacturer's protocol. GST-tagged Flfl $^{\mathrm{N}}, \mathrm{Flfl}^{\mathrm{M}}, \mathrm{Flfl}^{\mathrm{C}}$, Flfl ${ }^{1-168}$

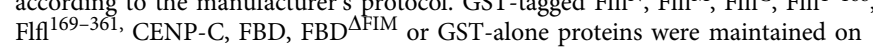
beads after immobilization and stored in PBS supplemented with $50 \%$ glycerol at $-20^{\circ} \mathrm{C}$. His-tagged proteins were affinity purified on Ni-NTA resin (Qiagen) according to the manufacturer's guide. After elution with $300 \mathrm{mM}$ imidazole, His::TEV::Flfl ${ }^{1-168}$ and His::TEV::CENP-C ${ }^{\mathrm{FBD}}$ were dialyzed against PBS for $4 \mathrm{~h}$ at $4^{\circ} \mathrm{C}$, and subsequently treated with His-tagged TEV protease (in house), re-incubated with Ni-NTA resin for $30 \mathrm{~min}$ on ice and supernatants were dialyzed against $\mathrm{PBS}+10 \%$ glycerol (PBSG) for $16 \mathrm{~h}$ at $4{ }^{\circ} \mathrm{C}$ and stored at $-20^{\circ} \mathrm{C}$.

Protein purification from cultured cells or embryos. We have previously published detailed protocols for sample preparation, protein A affinity purification and proteomic analysis in refs 45,46 . Briefly, $\sim 10^{9} \mathrm{D}$.Mel- 2 cells expressing protein A-tagged CENP-C, Flfl, Flfl ${ }^{1-168}$ or Flfl ${ }^{169-973}$ were lysed in $8 \mathrm{ml}$ extraction buffer (EB; $50 \mathrm{mM}$ HEPES pH 7.5, $100 \mathrm{mM} \mathrm{CH}_{3} \mathrm{COOK}, 100 \mathrm{mM} \mathrm{NaCl}, 50 \mathrm{mM} \mathrm{KCl}$, $2 \mathrm{mM} \mathrm{MgCl}_{2}, 2 \mathrm{mM}$ EGTA-Na, $5 \mathrm{mM}$ DTT, 0.5\% NP-40, 5\% glycerol and complete protease inhibitor cocktail) on ice using Power Gen 125 homogenizer (Fisher Scientific). Embryos ( $1 \mathrm{~g}$ ) expressing protein A-tagged CENP-C or Flfl were homogenized in $8 \mathrm{ml} \mathrm{EB}$ on ice using Dounce tissue grinder (Wheaton). Homogenates were treated with $2,000 \mathrm{Kunitz}$ units of DNase I (Sigma, D4263) for $5 \mathrm{~min}$ at $37^{\circ} \mathrm{C}$ and $10 \mathrm{~min}$ at $25^{\circ} \mathrm{C}$ and centrifuged $\left(4^{\circ} \mathrm{C}, 10 \mathrm{~min}, 10,000 \mathrm{~g}\right)$. 
Clarified lysates were mixed with rabbit immunoglobulin-G-conjugated Dynabeads (Life Technologies, 14302D) for $2 \mathrm{~h}$ at $4{ }^{\circ} \mathrm{C}$, beads were washed four times in EB and proteins were eluted with $1 \mathrm{M} \mathrm{NH}_{4} \mathrm{OH}\left(10 \mathrm{~min}\right.$ at $\left.25^{\circ} \mathrm{C}\right)$. Eluates were acetone precipitated and samples were analyzed by mass spectrometry.

Immunoaffinity purification of FLAG-tagged proteins was performed as follows: (1) Large scale: FLAG::CENP-C ${ }^{\text {FBD }}$, FLAG::CENP-C ${ }^{\text {WT }}$ or FLAG::CENP$\mathrm{C}^{\Delta \mathrm{FIM}}$ were affinity purified from $\sim 10^{9}$ stably transfected D.Mel-2 cells on anti$\mathrm{FLAGM}_{2}$ magnetic beads (Sigma, M8823) as described above. Purified complexes were analyzed by immunoblotting or mass spectrometry. (2) Small-scale for the $\lambda$-PPase band-shift assay: stably transfected D.Mel- 2 cells $\left(1-5 \times 10^{6}\right.$ cells per well $)$ expressing FLAG::CENP-C ${ }^{\mathrm{FBD}}$ were treated with DMSO (carrier control), $50 \mathrm{nM}$ okadaic acid $\left(3 \mathrm{~h}\right.$ at $\left.25^{\circ} \mathrm{C}\right)$ or double-stranded RNAs (dsRNAs) targeting flfl, $p p 4 c$ or kan for RNA-mediated interference (RNAi). Cells were lysed in EB by passing a cell suspension through a G25 needle (five times) followed by centrifugation $\left(4^{\circ} \mathrm{C}\right.$, $10 \mathrm{~min}, 21,000 \mathrm{~g}$ ). Supernatants were incubated with anti-FLAGM ${ }_{2}$ magnetic beads $\left(4{ }^{\circ} \mathrm{C}, 3 \mathrm{~h}, 15\right.$ r.p.m.) and bound proteins were eluted with $1 \mathrm{M} \mathrm{NH}_{4} \mathrm{OH}$ (room temperature, $5 \mathrm{~min}$ ), precipitated with ice-cold acetone and used in a $\lambda$-PPase assay.

Small-scale GFP purification was performed from 1-5 $\times 10^{6}$ D.Mel-2 cells expressing wild-type or $\triangle$ FIM variants of FLAG::CENP-C and transiently cotransfected with GFP-tagged Flfl, Flff ${ }^{1-168}$ or Flff ${ }^{169-973}$ (in pMT-GFP) on GFPTrap beads (ChromoTek, gta) following the protocol detailed above (see small-scale $\mathrm{FLAGM}_{2}$ IP). Protein complexes were eluted with $1 \times$ Laemmli sample buffer and analyzed by immunoblotting.

To pull down embryonic PP4, a wild-type (Oregon-R) syncytial embryo extract was incubated with GST (control) or GST::CENP-C ${ }^{\mathrm{BBD}}$ (for $3 \mathrm{~h}$ at $4{ }^{\circ} \mathrm{C}$, with gentle rotation) immobilized on Glutathione Sepharose $4 \mathrm{~b}$ resin. The beads were then washed five times in EB, resuspended in Laemmli sample buffer, boiled and subjected to SDS-PAGE.

Mass spectrometry. Mass spectrometric analyses of protein samples obtained after affinity purifications were performed at Mass Spectrometry Laboratory, Institute of Biochemistry and Biophysics, Polish Academy of Sciences (Warsaw, Poland) ${ }^{21}$. Samples were digested with trypsin (Promega V5111) and peptide mixtures were analyzed by liquid chromatography-tandem mass spectrometry (LC-MS/MS) using Nano-Acquity (Waters) LC system and Orbitrap Velos mass spectrometer (Thermo Electron Corp.). MS/MS raw data were analyzed by Mascot Distiller followed by Mascot Search (Matrix Science) against FlyBase database.

In vitro complex formation. Recombinant $\mathrm{Flfl}^{1-168}$ or $\mathrm{CENP}-\mathrm{C}^{\mathrm{FBD}}$ were loaded $\left(\mathrm{v}=0.5 \mathrm{ml} \mathrm{min}^{-1} ; \mathrm{V}=0.5 \mathrm{ml}\right.$, respectively) onto a Superdex 200 size exclusion column (GE Healthcare), and individual fractions were analyzed by SDS-PAGE followed by Coomassie brilliant blue (CBB) staining. To reconstitute the dimeric complex in vitro, Flff ${ }^{1-168}$ and CENP-C ${ }^{\mathrm{BBD}}$ were mixed in an $\sim 1: 1$ molar ratio, incubated on ice for $16 \mathrm{~h}$, centrifuged $\left(4^{\circ} \mathrm{C}, 10 \mathrm{~min}, 21,000 \mathrm{~g}\right)$ and loaded onto the Superdex 200 column.

IVTT and binding assays. For the interaction studies ${ }^{35} \mathrm{~S}$-methionine-labelled Flfl, Flff $^{1-168}$, R2, PP4c, CENP-C-fl, CENPC-N ${ }^{\prime}$, CENPC-C' or C1-C11 (see Fig. 1e) fragments of CENPC-C were expressed in vitro using the $\mathrm{T}_{\mathrm{N}} \mathrm{T}$ T7 Quick Coupled Transcription/Translation System (Promega, L1170). Hundred nanograms of purified PCR fragments (C1-C11, Flfl ${ }^{1-168}$ ) or recombinant plasmids (Flfl, R2 or PP4c in pETDuet-1; CENP-C-fl, CENPC-N ${ }^{\prime}$ or CENPC-C' in pDEST17) were added to a $30 \mu \mathrm{l}$ reaction mixture (containing $\mathrm{T}_{\mathrm{N}} \mathrm{T}$ Quick Master Mix, RNasin Plus RNase Inhibitor (Promega, N2611), T7 $\mathrm{T}_{\mathrm{N}} \mathrm{T}$ PCR Enhancer, protease inhibitor cocktail and $0.5 \mathrm{MBq}$ Methionine-L $\left[{ }^{35} \mathrm{~S}\right]$ (Perkin Elmer, NEG709A001MC)), and incubated at $30^{\circ} \mathrm{C}$ for $60 \mathrm{~min}$. The mixture was centrifuged at $21,000 \mathrm{~g}$ at $25^{\circ} \mathrm{C}$ for $5 \mathrm{~min}$. The supernatant (IVTT input) was divided into equal parts and used for an in vitro binding assay in which GST only served as the negative control and other GST-tagged proteins were used as a bait. Bait proteins immobilized on Glutathione Sepharose $4 \mathrm{~b}$ resin were resuspended in $800 \mu \mathrm{l}$ of binding buffer $(50 \mathrm{mM}$ HEPES $\mathrm{pH} 7.4,150 \mathrm{mM} \mathrm{NaCl}, 1 \mathrm{mM} \mathrm{MgCl}, 1 \mathrm{mM}$ EGTA, $1 \mathrm{mM}$ DTT, $0.1 \%$ Triton X-100, complete protease inhibitor cocktail and $0.5 \mathrm{mg} \mathrm{ml}^{-1} \mathrm{BSA}$ ), mixed with IVTTexpressed ${ }^{35} \mathrm{~S}$-Met-labelled prey and incubated for $1 \mathrm{~h}$ at $25^{\circ} \mathrm{C}$ (with gentle rotation). Then beads were washed with washing buffer (binding buffer without BSA), transferred into new tubes and boiled in Laemmli sample buffer. Proteins were separated by SDS-PAGE and gels were then stained with Coomassie brilliant blue, dried and directly used for autoradiography. Exposure to hypersensitive film (Kodak BioMax MS film, 8222648) was carried out at $-80^{\circ} \mathrm{C}$.

Peptide array. Two peptide arrays were generated (Peptide Synthesis Laboratory, CR UK LRI, London): (1) interaction array: 82 different 20 -mer peptides each shifted by 1 aa and covering the whole sequence of CENP-C ${ }^{\mathrm{FBD}}$ were spotted onto a cellulose membrane; (2) substitution array: each and every residue in the 19-mer FIM motif (1048-PDESSADVVFKKPLAPAPR-1066) was substituted with 19 individual different aa giving 380 peptides in total, which were spotted onto a cellulose membrane. Membranes were activated by washing in 50\% ethanol and $10 \%$ glacial acetic acid for $1 \mathrm{~h}$ and then washed three times in Buffer A $(50 \mathrm{mM}$ Tris, pH 7.5, $100 \mathrm{mM} \mathrm{NaCl}$ and $1 \mathrm{mM}$ DTT) for $10 \mathrm{~min}$ each. Hundred nanomolar high purity untagged Flfl ${ }^{1-168}$ in Buffer A was left to incubate with the arrays at $4{ }^{\circ} \mathrm{C}$ overnight with continuous shaking. The membranes were then washed with Buffer A and incubated with anti-Flfl antibody in Buffer B (Buffer A supplemented with $0.1 \%$ Tween- 20 and $5 \%$ milk powder) for $3 \mathrm{~h}$ at room temperature. After further washes, spots with bound Flfl ${ }^{1-168}$ were detected using goat anti-rat immunoglobulin-G-horseradish peroxidase-conjugated secondary antibody $(2 \mathrm{~h}$ at room temperature) and visualized by chemiluminescence according to the manufacturer's instruction (Merck Millipore, WBKLS0500).

$\lambda$-PPase band-shift assay. Immunaffinity-purified FLAG::CENP-C $\mathrm{C}^{\mathrm{FBD}}$ and its phosphorylated forms were treated with exogenous $\lambda$-PPase (NEB, P0753): purified protein precipitates were resuspended in $\lambda$-PPase buffer supplemented with $1 \mathrm{mM}$ $\mathrm{MnCl}_{2}$. Samples were divided into two equal portions and incubated at $30^{\circ} \mathrm{C}$ in the presence or absence of $\lambda$-PPase for indicated times $(\max 2 \mathrm{~h})$. The reaction was stopped by adding Laemmli sample buffer followed by heat inactivation (for $5 \mathrm{~min}$ at $95^{\circ} \mathrm{C}$ ). Samples were subjected to Phos-tag-containing SDS-PAGE.

Phos-tag SDS-PAGE. For the better separation of phosphorylated FLAG::CENP$\mathrm{C}^{\mathrm{FBD}}$ species, protein samples were subjected to $15 \%$ SDS-PAGE containing $25 \mu \mathrm{M}$ Phos-tag (Wako, AAL-107) in the presence of $70 \mu \mathrm{M} \mathrm{MnCl}_{2}$. Proteins were blotted to nitrocellulose membrane according to the manufacturer.

Antibodies. Affinity-purified GST-tagged $\mathrm{Flfl}^{\mathrm{N}}$, PP4c $\mathrm{c}^{1-50}$ or CENP-C $\mathrm{C}^{1202-1411}$ and $\mathrm{R} 2::$ His were further purified by size exclusion chromatography (Superdex $75, \mathrm{GE}$ Healthcare) in PBS and used as antigens to immunize rats (anti-Flfl and antiCENP-C by IBMC, Portugal), a mouse (anti-PP4c by Harlan, UK) or a rabbit (antiR2 by Harlan). The specificity of the antibodies was confirmed by immunoblotting (Supplementary Fig. 1a) after gene-specific RNAi in D.Mel-2 cells. The following antibodies were used in IB or IF experiments: rat anti-Flfl serum (IB: 1:10,000, IF: 1,000), mouse anti-PP4c serum (IB: 1:3,000), rat anti-CENP-C serum (IB: 1:3,000, IF: 1:1,000), mouse anti-FLAGM 2 (Sigma, F3165; IB: 1:1,0000, IF: 1:5,000), mouse anti- $\alpha$ Tubulin (clone DM1A; Sigma, T9026; IB: 1:10,000, IF: 1:500) and mouse anti-GFP (Roche, 11814460001; IB: 1:2,000, IF:1:1,000). Chicken anti-CID purified antibody (IF: 1:2,000), rabbit anti-Mis12 serum (IF: 1:500), rabbit antiNsl1 serum (IF: 1:1,000), sheep anti-Spc105 serum (IF: 1:1,000), rabbit anti-Ndc80 serum (1:500) and rabbit anti-Spd2 (IF: 1:2,000) antibodies were generated and used in previous studies in our laboratory ${ }^{21,47,48}$. Secondary antibodies for IB or IF were obtained from Jackson ImmunoResearch (horseradish peroxidase or DyLight conjugates) or Life Technologies (AlexaFluor conjugates) and used at 1:10,000 (IB) or 1:500 (IF) dilution.

Transgenic flies. Transgenic Drosophila melanogaster stocks constitutively expressing protein A-tagged CENP-C (w; P(maternal atub-Cenp-C::PrA)) or Flfl $(w ;+; P($ maternal $\alpha t u b-\operatorname{Pr} A:: F l f l))$ in female germline were made using standard P-element transformation (Fly Facility, Department of Genetics, University of Cambridge). Fly stocks were cultured at $25^{\circ} \mathrm{C}$ on standard Drosophila food. Fly stocks expressing the transgenic proteins in a comparable (same or lower) level than that of the endogenous protein were used in proteomic studies.

Cell cultures. D.Mel-2 cells (Life Technologies) were grown in Express Five SFM medium (Life Technologies, 10486-025) supplemented with $2 \mathrm{mM}$ L-glutamine (25030-024) and Pen Strep (15140-122) according to standard procedures. Protein A:::Flfl, protein A::Flf ${ }^{1-168}$, protein A::Flfl ${ }^{169-973}$, CENP-C::protein A, FLAG:::CENP-C $^{\mathrm{FD}}$, FLAG:::CENP-C ${ }^{\mathrm{WT}}$, FLAG::CENP-C ${ }^{\triangle \mathrm{FIM}}$, Flfl:::FLAG, FLAG::Flf1 ${ }^{1-168}$, GFP::CENP-C ${ }^{\text {WT }} /$ FLAG::Flf1 ${ }^{1-168}$, GFP::CENP-C ${ }^{\Delta \mathrm{FIM}} / \mathrm{FLAG}::$ Flf $1^{1-168}$, FLAG::PP4c $c^{\text {WT }}$ and FLAG::PP4c $c^{\text {PhD }}$ stable cell lines were established using FuGENE HD Transfection Reagent (Promega, E2311) following standard procedures $^{21}$. Briefly, $3 \mu \mathrm{g}$ of DNA was mixed with $15 \mu \mathrm{l}$ of the reagent in $150 \mu \mathrm{l}$ of nuclease-free water for each transfection mixture and incubated at room temperature for $15 \mathrm{~min}$. Then, each mixture was added drop wise to a well of a six-well plate, where cells were previously seeded in $2 \mathrm{ml}$ of medium at $40-60 \%$ confluency. The antibiotic selection started $48 \mathrm{~h}$ post-transfection and was carried out according to standard procedures ${ }^{45}$.

RNAi and immunostaining of cells. The sequences of primers used to amplify dsRNAs for RNAi experiments are given in Supplementary Table 7. For Flfl, PP4c and CENP-C more than one dsRNA was generated. We have not noticed differences between them, in terms of effectiveness of the knockdown or a phenotype. The time for maximal protein depletion was empirically determined; in general the most severe phenotype was attained after two sequential rounds of RNAi. Cells were transfected with dsRNAs using TransFast (Promega, E2431) and then plated on non-treated or $0.5 \mathrm{mg} \mathrm{ml}^{-1}$ concanavalin-A-coated cover slips, fixed with $4 \%$ formaldehyde and immunostained ${ }^{47,48}$. Briefly, fixed cells were blocked in $3 \%$ BSA, $0.5 \%$ Triton X-100 in PBS, then incubated in primary antibody-containing PBT (1\% BSA, $0.1 \%$ Triton X-100 in PBS) for $2-4 \mathrm{~h}$, followed by three washes in PBT, $1 \mathrm{~h}$-long incubation in secondary antibody-containing PBT and three more washes 
in PBT. After this, cover slips were rinsed with pure water and mounted on slides with ProLong Gold antifade reagent (Life Technologies, P36934).

Microscopy. Images were acquired on a Zeiss Axiovert $200 \mathrm{M}$ microscope (objective $\times 100$ /numerical aperture 1.4 ) with a Cool-SNAP HQ camera (Photometrics) using MAG Biosystems Software-Metamorph (Molecular Devices). Images showing Flfl, Flfl::FLAG or FLAG::Flfl ${ }^{1-168}$ localization were acquired using a Zeiss LSM 510 Meta Confocal Microscope ( $\times 100$ objective) using LSM510 software (release version 4.2 SP1, Carl Zeiss MicroImaging) and processed using ImageJ (NIH, USA). Line scans were done using ImageJ and values were imported to MS Excel, which was used to prepare plots.

Phenotypic analysis. The CENP-C displacement phenotype was most reliably scored in cells in which the spindle axis was parallel to the cover slip with well separated centrosomes, as shown by Spd 2 staining, and where the chromosomes were largely congressed at the equator (Fig. 4a). This prevented false positives due to centrosome proximal to centromeric signals. It is therefore likely that our phenotypic counts are underestimates of the penetrance of the defect. Data from four independent RNAi experiments were analyzed using GraphPad Prism software to produce the graph in Fig. $4 \mathrm{~b}$. The expressions of wild-type and $\Delta F I M$ versions of CENP-C were assessed after four RNAi experiments (Fig. 4c) and wildtype and $\mathrm{PhD}$ versions of PP4c after two RNAi experiments (Fig. 4d). A minimum of 50 mitotic cells were scored for each variant within each experiment. In experiments, which involved replacement of endogenous CENP-C with the transgenic CENP-C constructs, only those cells were scored that showed normal levels of CENP-C.

Crystallographic methods. Crystals of native protein-peptide complex were grown in sitting drops by the vapour diffusion method ${ }^{49}$. Solution of protein at $22 \mathrm{mg} \mathrm{ml}^{-1}$ was incubated overnight with peptide (PDESSADVVFKKPLAPAPR) in a ratio of $1: 1.3$. Crystals of complex were grown by mixing $0.2 \mu \mathrm{l}$ of this solution with a $1: 1$ dilution of $1 / 2$ reservoir buffer (3.31 M Ammonium Sulfate, 9.5\% Glycerol) and 1/2 Silver Bullet screen (Hampton Research; 0.2\% w/v 4-Aminobenzoic, $0.2 \% \mathrm{w} / \mathrm{v}$ Azelaic acid, $0.2 \% \mathrm{w} / \mathrm{v}$ o-Sulfobenzoic acid monoammonium salt, $0.2 \% \mathrm{w} / \mathrm{v}$ p-Coumaric acid, $0.2 \% \mathrm{w} / \mathrm{v}$ Sodium 4 -aminosalicylate dihydrate and $20 \mathrm{mM}$ HEPES sodium $\mathrm{pH}$ 6.8) with distilled water. Crystals grew in space group P6 $6_{1}$ (unit cell dimensions: $a=b=67.75 \AA, c=53.37 \AA$ ) to a size of $0.4 \times 0.2 \times 0.1 \mathrm{~mm}$. Under the assumption of one protein molecule per asymmetric unit, a $V_{\mathrm{M}}$ value of $2.46 \AA^{3} \mathrm{Da}^{-1}$ corresponding to a solvent content of $49.9 \%$ was calculated ${ }^{50}$. Crystals used for data collection were soaked in $3.4 \mathrm{M}$ sodium malonate for a period of $2 \mathrm{~min}$, transferred to loops and immersed in liquid nitrogen. X-ray diffraction data were collected at beamline ID29 (see ref. 51) of the European Synchrotron Radiation Facility. Data used to solve the structure were collected from a single crystal flash frozen at $-180^{\circ} \mathrm{C}$. All data were processed and scaled using $\mathrm{XDS}^{52}$. Data collection statistics are shown in Table 3.

The structure of Flfl ${ }^{1-122}$ was solved by molecular replacement using the programme Mr Bump ${ }^{53}$ and two structures of RanBD and Spred-1 domains (PDB i.d. 1XOD, 1RRP) with a sequence identity of $20 \%$ as search models in a Phaser ensemble. The structure was iteratively rebuilt using $\operatorname{Coot}^{54}$ and refined with Refmac5 (see ref. 55) and phenix.refine ${ }^{56}$. The peptide sequence was docked after refinement for Flfl ${ }^{1-122}$ alone had converged, and anisotropic B-factor parameterization was employed for all non-water atoms. The structure was validated using tools from the Molprobity suite ${ }^{57}$, which showed $99 \%$ of residues to be in the favoured Ramachandran region and gave an overall clash score of 0.52 .

Image processing. Scanned autoradiographs, gels and immunoblots were cropped and compiled into figures using Adobe Photoshop and Illustrator CS6. Uncropped scans are provided in Supplementary Figs 5-9.

\section{References}

1. Barr, F. A., Elliott, P. R. \& Gruneberg, U. Protein phosphatases and the regulation of mitosis. J. Cell Sci. 124, 2323-2334 (2011).

2. Wurzenberger, C. \& Gerlich, D. W. Phosphatases: providing safe passage through mitotic exit. Nat. Rev. Mol. Cell Biol. 12, 469-482 (2011).

3. Cohen, P. T., Philp, A. \& Vazquez-Martin, C. Protein phosphatase 4--from obscurity to vital functions. FEBS Lett. 579, 3278-3286 (2005).

4. Zhang, X. et al. Histone deacetylase 3 (HDAC3) activity is regulated by interaction with protein serine/threonine phosphatase 4. Genes Dev. 19, 827-839 (2005).

5. Lee, D. H. et al. Phosphoproteomic analysis reveals that PP4 dephosphorylates KAP-1 impacting the DNA damage response. EMBO J. 31, 2403-2415 (2012).

6. Lee, D. H. et al. Dephosphorylation enables the recruitment of 53BP1 to double-strand DNA breaks. Mol. Cell 54, 512-525 (2014).

7. Shaltiel, I. A. et al. Distinct phosphatases antagonize the p53 response in different phases of the cell cycle. Proc. Natl Acad. Sci. USA 111, 7313-7318 (2014)
8. Chen, F. et al. Multiple protein phosphatases are required for mitosis in Drosophila. Curr. Biol. 17, 293-303 (2007).

9. Schmitz, M. H. et al. Live-cell imaging RNAi screen identifies PP2A-B55alpha and importin-betal as key mitotic exit regulators in human cells. Nat. Cell Biol. 12, 886-893 (2010).

10. Kittler, R. et al. An endoribonuclease-prepared siRNA screen in human cells identifies genes essential for cell division. Nature 432, 1036-1040 (2004).

11. Gingras, A. C. et al. A novel, evolutionarily conserved protein phosphatase complex involved in cisplatin sensitivity. Mol. Cell Proteomics 4, 1725-1740 (2005).

12. Gavin, A.-C. et al. Functional organization of the yeast proteome by systematic analysis of protein complexes. Nature 415, 141-147 (2002).

13. Ho, Y. et al. Systematic identification of protein complexes in Saccharomyces cerevisiae by mass spectrometry. Nature 415, 180-183 (2002).

14. Zarske, M. \& Hafen, E. 44th Annual Drosophila Research Conference 5-9 (The Genetics Society of America, 2003).

15. Chen, G. I. et al. PP4R4/KIAA1622 forms a novel stable cytosolic complex with phosphoprotein phosphatase 4. J. Biol. Chem. 283, 29273-29284 (2008).

16. Voss, M. et al. Protein phosphatase 4 is phosphorylated and inactivated by Cdk in response to spindle toxins and interacts with gamma-tubulin. Cell Cycle $\mathbf{1 2}$ 2876-2887 (2013).

17. Lyu, J. et al. Protein phosphatase 4 and Smek complex negatively regulate Par3 and promote neuronal differentiation of neural stem/progenitor cells. Cell Rep. 5, 593-600 (2013).

18. Ma, H. et al. Psy2 targets the PP4 family phosphatase Pph3 to dephosphorylate Mth1 and repress glucose transporter gene expression. Mol. Cell Biol. 34, 452-463 (2014).

19. Sousa-Nunes, R., Chia, W. \& Somers, W. G. Protein phosphatase 4 mediates localization of the Miranda complex during Drosophila neuroblast asymmetric divisions. Genes Dev. 23, 359-372 (2009).

20. Wolff, S. et al. SMK-1 an essential regulator of DAF-16-mediated longevity. Cell 124, 1039-1053 (2006).

21. Przewloka, M. R. et al. CENP-C is a structural platform for kinetochore assembly. Curr. Biol. 21, 399-405 (2011).

22. Screpanti, E. et al. Direct binding of Cenp-C to the Mis12 complex joins the inner and outer kinetochore. Curr. Biol. 21, 391-398 (2011).

23. Ball, L. J., Jarchau, T., Oschkinat, H. \& Walter, U. EVH1 domains: structure, function and interactions. FEBS Lett. 513, 45-52 (2002).

24. Niebuhr, K. et al. A novel proline-rich motif present in ActA of Listeria monocytogenes and cytoskeletal proteins is the ligand for the EVH1 domain, a protein module present in the Ena/VASP family. EMBO J. 16, 5433-5444 (1997).

25. Holm, L. \& Rosenstrom, P. Dali server: conservation mapping in 3D. Nucleic Acids Res. 38, W545-W549 (2010).

26. Prehoda, K. E., Lee, D. J. \& Lim, W. A. Structure of the enabled/VASP homology 1 domain-peptide complex: a key component in the spatial control of actin assembly. Cell 97, 471-480 (1999).

27. Peterson, F. C. \& Volkman, B. F. Diversity of polyproline recognition by EVH1 domains. Front. Biosci. (Landmark Ed.) 14, 833-846 (2009).

28. Williamson, M. P. The structure and function of proline-rich regions in proteins. Biochem. J. 297 Pt 2 249-260 (1994).

29. Lim, W. A., Richards, F. M. \& Fox, R. O. Structural determinants of peptidebinding orientation and of sequence specificity in $\mathrm{SH} 3$ domains. Nature 372, 375-379 (1994)

30. Feng, S., Chen, J. K., Yu, H., Simon, J. A. \& Schreiber, S. L. Two binding orientations for peptides to the Src SH3 domain: development of a general model for SH3-ligand interactions. Science 266, 1241-1247 (1994).

31. Harmer, N. J., Sivak, J. M., Amaya, E. \& Blundell, T. L. 1.15 A crystal structure of the X. tropicalis Spred1 EVH1 domain suggests a fourth distinct peptidebinding mechanism within the EVH1 family. FEBS Lett. 579, 1161-1166 (2005).

32. Beneken, J. et al. Structure of the Homer EVH1 domain-peptide complex reveals a new twist in polyproline recognition. Neuron 26, 143-154 (2000).

33. Myles, T., Schmidt, K., Evans, D. R., Cron, P. \& Hemmings, B. A. Active-site mutations impairing the catalytic function of the catalytic subunit of human protein phosphatase $2 \mathrm{~A}$ permit baculovirus-mediated overexpression in insect cells. Biochem. J. 357, 225-232 (2001).

34. Fisher, D., Krasinska, L., Coudreuse, D. \& Novak, B. Phosphorylation network dynamics in the control of cell cycle transitions. J. Cell Sci. 125, 4703-4711 (2012).

35. Qian, J., Winkler, C. \& Bollen, M. 4D-networking by mitotic phosphatases. Curr. Opin. Cell Biol. 25, 697-703 (2013).

36. Kustatscher, G. et al. Proteomics of a fuzzy organelle: interphase chromatin. EMBO J. 33, 648-664 (2014)

37. Shi, Y. Serine/threonine phosphatases: mechanism through structure. Cell 139, 468-484 (2009).

38. Orr, B. \& Sunkel, C. E. Drosophila CENP-C is essential for centromere identity. Chromosoma 120, 83-96 (2011). 
39. Bodenmiller, B. et al. PhosphoPep--a phosphoproteome resource for systems biology research in Drosophila Kc167 cells. Mol. Syst. Biol. 3, 139 (2007).

40. Zhai, B., Villen, J., Beausoleil, S. A., Mintseris, J. \& Gygi, S. P. Phosphoproteome analysis of Drosophila melanogaster embryos. J. Proteome Res. 7, 1675-1682 (2008).

41. Erhardt, S. et al. Genome-wide analysis reveals a cell cycle-dependent mechanism controlling centromere propagation. J. Cell Biol. 183, 805-818 (2008).

42. Toyo-oka, K. et al. Protein phosphatase 4 catalytic subunit regulates Cdk1 activity and microtubule organization via NDEL1 dephosphorylation. J. Cell Biol. 180, 1133-1147 (2008).

43. Stehman, S. A., Chen, Y., McKenney, R. J. \& Vallee, R. B. NudE and NudEL are required for mitotic progression and are involved in dynein recruitment to kinetochores. J. Cell Biol. 178, 583-594 (2007).

44. Wang, S. et al. Nudel/NudE and Lis1 promote dynein and dynactin interaction in the context of spindle morphogenesis. Mol. Biol. Cell 24, 3522-3533 (2013).

45. D'Avino, P. P. et al. Isolation of protein complexes involved in mitosis and cytokinesis from Drosophila cultured cells. Methods Mol. Biol. 545, 99-112 (2009).

46. Lipinszki, Z. et al. Affinity purification of protein complexes from Drosophila embryos in cell cycle studies. Methods Mol. Biol. 1170, 571-588 (2014).

47. Venkei, Z., Przewloka, M. R. \& Glover, D. M. Drosophila Mis12 complex acts as a single functional unit essential for anaphase chromosome movement and a robust spindle assembly checkpoint. Genetics 187, 131-140 (2011).

48. Przewloka, M. R. et al. Molecular analysis of core kinetochore composition and assembly in Drosophila melanogaster. PLoS ONE 2, e478 (2007).

49. Wlodawer, A. \& Hodgson, K. O. Crystallization and crystal data of monellin. Proc. Natl Acad. Sci. USA 72, 398-399 (1975).

50. Matthews, B. W. Solvent content of protein crystals. J. Mol. Biol. 33, 491-497 (1968).

51. de Sanctis, D. et al. ID29: a high-intensity highly automated ESRF beamline for macromolecular crystallography experiments exploiting anomalous scattering. J. Synchrotron Radiat. 19, 455-461 (2012).

52. Kabsch, W. Xds. Acta Crystallogr. D Biol. Crystallogr. 66, 125-132 (2010).

53. Keegan, R. M. \& Winn, M. D. MrBUMP: an automated pipeline for molecular replacement. Acta Crystallogr. D Biol. Crystallogr. 64, 119-124 (2008).

54. Emsley, P., Lohkamp, B., Scott, W. G. \& Cowtan, K. Features and development of Coot. Acta Crystallogr. D Biol. Crystallogr. 66, 486-501 (2010).

55. Murshudov, G. N. et al. REFMAC5 for the refinement of macromolecular crystal structures. Acta Crystallogr. D Biol. Crystallogr. 67, 355-367 (2011).

56. Adams, P. D. et al. PHENIX: a comprehensive Python-based system for macromolecular structure solution. Acta Crystallogr. D Biol. Crystallogr. 66, 213-221 (2010)

57. Chen, V. B. et al. MolProbity: all-atom structure validation for macromolecular crystallography. Acta Crystallogr. D Biol. Crystallogr. 66, 12-21 (2010).
58. Heeger, S. et al. Genetic interactions of separase regulatory subunits reveal the diverged Drosophila Cenp-C homolog. Genes Dev. 19, 2041-2053 (2005).

\section{Acknowledgements}

We are thankful to Magda Richter (Institute of Biochemistry and Biophysics (IBB PAS), Warsaw, Poland) and Renier Heijkants (Leiden University Medical Center, Netherlands) for their help with making DNA constructs, the Drosophila Genomics Resource Centre (supported by NIH grant 2P40OD010949-10A1) for the complementary DNA clones and Andor Udvardy (Institute of Biochemistry, Biological Research Centre of the Hungarian Academy of Sciences (HAS-BRC)) for the critical reading of the manuscript. We also wish to thank the London Research Institute Peptide Chemistry facility, and Andrew Purkiss for assistance with data collection, and Janusz Debski and Michal Dadlez from the MS Lab (IBB PAS, Poland) for their assistance with proteomic analyses. Z.L. is on leave from HAS-BRC (Institute of Biochemistry) and was supported by the LongTerm Fellowship of the Federation of European Biochemical Societies (FEBS). This work was supported financially by grants from Cancer Research UK (C3/A11431) and the Medical Research Council (G1001696) to D.M.G.

\section{Author contributions}

Z.L. performed interaction and in vitro assays, protein purifications from cultured cells and embryos, proteomic analysis, mutagenesis and antibody production. S.L. and M.R.S. undertook crystallographic experiments. M.S.S. contributed to the phenotypic analysis of cultured cells. M.R.P. performed protein purifications from cultured cells, proteomic analysis and cell biology experiments. Z.L., M.R.P., M.R.S. and D.M.G. planned the experiments and wrote the paper that was discussed by all authors.

\section{Additional information}

Accession code: The atomic coordinates and structure factors have been deposited in the Protein Data Bank under accession code 4WSF.

Supplementary Information accompanies this paper at http://www.nature.com/ naturecommunications

Competing financial interests: The authors declare no competing financial interests.

Reprints and permission information is available online at http://npg.nature.com/ reprintsandpermissions/

How to cite this article: Lipinszki, Z. et al. Centromeric binding and activity of Protein Phosphatase 4. Nat. Commun. 6:5894 doi: 10.1038/ncomms6894 (2015).

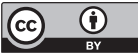

This work is licensed under a Creative Commons Attribution 4.0 International License. The images or other third party material in this article are included in the article's Creative Commons license, unless indicated otherwise in the credit line; if the material is not included under the Creative Commons license, users will need to obtain permission from the license holder to reproduce the material. To view a copy of this license, visit http://creativecommons.org/licenses/by/4.0/ 